\title{
Detecting Tourism Typologies of Regional Destinations Based on Their Spatio-Temporal and Socioeconomic Performance: A Correlation-Based Complex Network Approach for the Case of Greece
}

\author{
Dimitrios Tsiotas $^{1,2, *(\mathbb{D})}$, Thomas Krabokoukis ${ }^{3}\left(\mathbb{D}\right.$ and Serafeim Polyzos ${ }^{3}$ \\ 1 Department of Regional and Economic Development, Agricultural University of Athens, \\ 11855 Athens, Greece \\ 2 School of Social Sciences, Hellenic Open University, 10677 Athens, Greece \\ 3 Department of Planning and Regional Development, University of Thessaly, 38221 Volos, Greece; \\ tkrabokoukis@uth.gr (T.K.); spolyzos@uth.gr (S.P.) \\ * Correspondence: tsiotas@aua.gr
}

check for updates

Citation: Tsiotas, D.; Krabokoukis, T.; Polyzos, S. Detecting Tourism Typologies of Regional Destinations Based on Their Spatio-Temporal and Socioeconomic Performance: A Correlation-Based Complex Network Approach for the Case of Greece. Tour. Hosp. 2021, 2, 113-139. https:// doi.org/10.3390/tourhosp2010007

Academic Editor: Brian Garrod

Received: 13 February 2021

Accepted: 20 February 2021

Published: 26 February 2021

Publisher's Note: MDPI stays neutral with regard to jurisdictional claims in published maps and institutional affiliations.

Copyright: (C) 2021 by the authors Licensee MDPI, Basel, Switzerland. This article is an open access article distributed under the terms and conditions of the Creative Commons Attribution (CC BY) license (https:// creativecommons.org/licenses/by/ $4.0 /)$.

\begin{abstract}
Within the context that tourism-seasonality is a composite phenomenon described by temporal, geographical, and socio-economic aspects, this article develops a multilevel method for studying time patterns of tourism-seasonality in conjunction with its spatial dimension and socio-economic dimension. The study aims to classify the temporal patterns of seasonality into regional groups and to configure distinguishable seasonal profiles facilitating tourism policy and development. The study applies a multilevel pattern recognition approach incorporating time-series assessment, correlation, and complex network analysis based on community detection with the use of the modularity optimization algorithm, on data of overnight-stays recorded for the time-period 1998-2018. The analysis reveals four groups of seasonality, which are described by distinct seasonal, geographical, and socio-economic profiles. Overall, the analysis supports multidisciplinary and synthetic research in the modeling of tourism research and promotes complex network analysis in the study of socio-economic systems, by providing insights into the physical conceptualization that the community detection based on the modularity optimization algorithm can enjoy to the real-world applications.
\end{abstract}

Keywords: tourism seasonality; modularity optimization algorithm; regional and tourism development; seasonality grouping; spatiotemporal patterns; pattern recognition

\section{Introduction}

A variety of theories and models have been developed over time aiming to study the uneven developmental dynamics that emerge between regions and to contribute to the academic dialogue towards the direction of seeking a solution to the regional problem that concerns the reduction of spatial inequalities [1-9]. In general, the uneven spatial development affects the economic growth [2,3], the quality of the environment, the culture, and the social conceptualization [4-6], and, therefore, it can be considered as a major driver for the sustainable economic development $[7,8]$. This aspect highlights the importance of studying spatial inequalities in the research of regional economics [1,9], where tourism is a major field due to its socio-economic configuration that affects the regional, national, and worldwide economic interaction and thus the economic development [8-10]. Provided that tourism is a time-variant socio-economic phenomenon that is by default equipped with a spatial reference, the study of tourism within a common temporal and spatial context [6-8] can provide insights towards the demand for integration, which can contribute to the multidisciplinary conceptualization of regional economics [9,11]. Amongst the many others, a major property of tourism [12-16], which diversely affects almost every destination [9,17], 
is related to the phenomenon of (the so-called) tourism-seasonality, which concerns the uneven distribution of tourism-demand along the period of the year [6,18]. The nature of this phenomenon is rather complex, as it can be deduced first by the definition of this term, which is composed by the concepts of tourism demand $[1,6,9,12,14-16,18]$, which is related to the intensity of the tourist load applied to a destination, time $[1,6,9,11,12,15,17]$, which describes how tourism demand is distributed through time, and space $[6,9,12,14-18]$, which describes those geographical features that link a destination with a specific pattern of seasonality. This 3D conceptualization allows considering corresponding spaces of embedding for the study of seasonality, such as the socioeconomic space, where social and market activities related to tourism demand are developed, the temporal space, which is the timeframe where socioeconomic forces evolve, and the geographical space, which is the spatial receptor where market activities apply throughout time. Based on this conceptualization, we construct Table A1 shown in the Appendix A, where modeling and implementation aspects of tourism seasonality extracted from the literature can be organized by these 3D conceptual approaches. This multi-block table reveals several aspects composing the complexity of tourism seasonality, which is related to diverse factors [18-28] that can be either environmental $[6,14]$, such as the geomorphology and climate [18,19], or social [20], such as the synergy among the destinations [24-26] and the traditions [28,29], or geographical $[9,25,30]$, such as the accessibility of destinations [25], or economic [1,9], such as the tourism-capacity [21], the competitiveness [22,23,27], the attractiveness of destinations [10], the configuration of local economies [15], and the type of tourism product [29] (see column B3, Table A1, Appendix A). As is evident in all such aspects of tourism-seasonality, the spatial dimension is an immanent (either directly or indirectly) in the conceptualization of the phenomenon [9].

However, in the current literature, the temporal dimension of tourism-seasonality is mainly examined [6,9] by using various methodologies that are applied within a certain geographical and socio-economic framework (column C1, Table A1, Appendix A) [9,14,31], but without considering how space affects the seasonality's temporal dynamics. For instance, a major class of research-studies examines the temporal aspect of seasonality by mainly analyzing the time-series configuration of a specific variable, for a certain destination $[14,15,32,33]$, without thus taking into account the variability in the seasonality's temporal patterns that are caused by the location. In this class, the variables that are most commonly used are (column B2, Table A1, Appendix A) the number of tourists (visitors), arrivals, and overnight-stays, whereas also some income-defined variables are used [9,30,31]. This uni-variable approach (column B1, Table A1, Appendix A) is usually sensitive to the subjectivity in the variables' selection [31] and to the sampling-rate, according to which the time-unit (e.g., months, days, etc.) is being defined [14,34]. On the other hand, another direction in the study of seasonality regards the computation of quantitative measures or indicators (column B4, Table A1, Appendix A) that are capable of capturing different aspects of this phenomenon (column B3, Table A1, Appendix A), such as concentration, scale, periodicity, or cyclical performance [9,35-37]. Some indicative measures of this category are the range of seasonality, the seasonality-ratio, the coefficient of variation (CV) and seasonal variation [35,36], the Gini coefficient, and the Theil index [9,37], some of which are rather useful due to their ability to decompose into components [38-41]. However, even in the most composite cases of these measures, such as in the case of the Gini coefficient and the Theil index, some critical information that is related to the seasonality (e.g., periodicity) can be lost $[14,36]$ due to restrictions concerning either the data configuration (e.g., annual reference) or the spatial embedding of seasonality that is usually approximating by averaging techniques $[15,39]$. Some other more composite indicators that were recently proposed in the literature, such as the Relative Seasonal Index-RSI [14,36] and the synthetic $\mathrm{DP}_{2}$ index [31], promise to overcome these common restrictions describing the established indicators $[9,14,36,42-50]$, but these composite indicators are also subjected to the restriction of uni-variable configuration and computational complexity due to higher demand in computations [9]. 
Despite that seasonality affects almost every tourism-destination (column C1, Table A1, Appendix A), in the current literature, the symbiotic relationship between seasonality and space does not seem to be studied in a comprehensive quantitative context. This observation is verified by the bi-dimensionality (column B1, Table A1, Appendix A) of the relevant research that was previously emerged [9], one pillar of which deals with the study of multivariate time (temporal) aspects of seasonality $[6,14,17,30-33,45]$ that is mainly applied within the context of a single destination, whereas the second one, which studies geographical aspects of seasonality, overlooks the effect that time induces to the spatial patterns of tourism-demand [42,43]. Some bright exceptions to this dual conceptualization of seasonality can be found in the works of $[4-6,9,17,44,49]$, which attempt to integrate the spatial and temporal dimension of this phenomenon through different methodological aspects, such as cluster analysis, econometric modeling, tourist area life cycle assessment, classification and dimension reduction modeling. However, such approaches rather highlight the demand for integration than adequately configure a comprehensive context for integrating the time (temporal) and geographical (spatial) dimensions of tourism-seasonality [9].

Aiming at serving the demand for integration, this paper proposes a new method for studying temporal patterns of tourism-seasonality in conjunction with their spatial information. The proposed method builds on a joint consideration of correlation and complex network analysis to convert into a complex network the temporal information of the seasonality patterns of the 51 (NUTS III) Greek regions, which are configured for the period 1998-2018, and then to classify these available patterns into communities, according to their level of connectivity in the network model. Complex network (or network) analysis is considered by many scholars as a separate discipline, called network science [51-54], uses the network paradigm to represent complex communication (or other interacting) systems as graphs, namely as pair-sets of nodes and edges that are converted into connectivity matrices, where many topological measures can be computed. In tourism research, network structures prevail [55-58] because tourism is by definition an act of interaction (or mobility) and thus the conceptualization of connectivity is by default applicable in the modeling of tourism systems. However, the network paradigm has not yet been sufficiently incorporated in tourism research and therefore there are many ongoing avenues of further research towards this direction [55-57]. For instance, a major benefit of the network conceptualization in the description of interconnected systems regards its ability to incorporate, within a single model, structural and functional (flow) information, at any scale (e.g., local, neighborhood, regional, or global), and thus to provide a dual microeconomic and macroeconomic description of real-world systems [58]. Within this context, this paper uses the network paradigm to model correlations between seasonality patterns as a complex network, which (according to the dual conceptualization of networks) allows incorporating topological information related to the connectivity of correlated data with the scale and variability information captured by correlation analysis. The study examines the case of Greece, which enjoys a considerable tourism specialization, where almost $20 \%$ of its GDP is related to direct tourism activities [46-51], it is a top-ranked in the EE27 in terms of the number of visitors [46], amongst which the 50-60\% of foreign arrivals is implemented in the high-season period of July to September [47]. Greece has more than 16,000 km of coastline and more than 1350 islands, islets, and rocky-islands [47], and its rich geomorphological configuration has led to a composite tourism product [50], which is unevenly distributed throughout the various tourism-destinations of the country [49-51].

Within this context, the proposed methodological framework allows classifying the Greek prefectures according to their seasonality patterns, aiming to be insightful about the spatial configuration of tourism-seasonality in Greece and how it can be managed in conjunction with the dynamics of the regional space. The main research question addressed in this paper is configured within an exploratory context and it concerns whether temporal patterns of tourism seasonality can be related to the spatial distribution and the socioeconomic attributes of the regional destinations in Greece. The overall approach can drive to more efficient and sustainable management, planning, and hospitality strategies 
in tourism, which can contribute the Greek tourism-destinations to the goal of balanced regional development.

The rest of this paper is structured as follows: Section 2 describes the methodology of the study, the available data, and the variables that are included in the analysis. Section 3 shows the results of the analysis and provides a discussion within the context of tourism management and regional economics. Finally, in Section 4 the conclusions are summarized.

\section{Methodology and Data}

This study configures a methodological framework for analyzing temporal patterns of tourism-seasonality amongst the 51 Greek regions and for classifying them into regional groups, according to their relevance in connectivity that is defined after applying complex network analysis to the seasonal data. The purpose of the analysis is to detect linear and non-linear commonalities in the temporal patterns of tourism-seasonality of the Greek regions, to categorize them into groups, and to detect distinctive seasonal profiles. Towards this direction, the proposed methodology builds on complex network analysis [51-54] that is applied to the seasonal data after converting them to graphs through a correlation-based criterion. In particular, the methodological framework of the study consists of the five steps shown in Figure 1.

STEP 1. Computation of seasonal patterns for each Greek region

STEP 5. Conclusion making

STEP 4. Further analysis on socioeconomic profiles of seasonal patterns

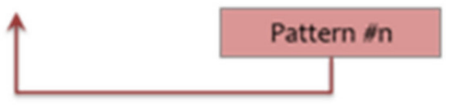

STEP 2. Analysis of seasonal patterns

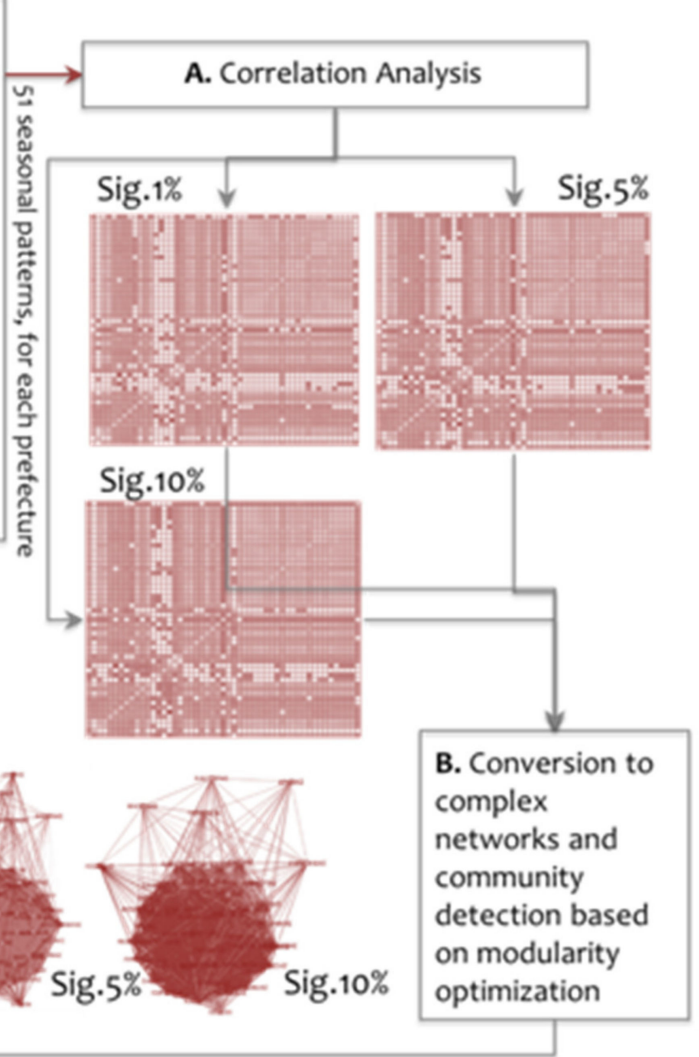

Figure 1. Conceptual diagram illustrating the methodology of the study.

At the first step, the seasonality-variables expressing the seasonality patterns of the Greek prefectures are computed, on data expressing the monthly number of total overnightstays per prefecture (NUTS III), which are recorded for the years from 1998 up to 2018. The available data were granted upon request by the Hellenic Statistical Authority [59] to be used under an exclusive license for this study. In particular, 51 seasonality-variables are configured, each one representing the time-series of the monthly overnight-stays recorded per prefecture (codes and variable-names are shown in Table A2, in the Appendix A). 
At the second step, the seasonality-variables are first included in a correlation analysis, where the Pearson's bivariate coefficients of correlations [60] are computed for all possible pairs of the available variables. The square table of correlation coefficients is then filtered according to the level of significance, where only significant coefficients are preserved. Therefore, for significances $1 \%, 5 \%$, and $10 \%$, this allows producing three correlation tables corresponding to a certain significance level. At next, each table is converted to a network (graph) model, each one expressing a weighted graph of 51 nodes, where the links have weights equal to the significant correlation coefficients, for this case.

Further, a community detection analysis [61] that builds on the modularity optimization algorithm of [62] is applied to each network model (corresponding to $1 \%, 5 \%$, and $10 \%$ levels of significance). This algorithm generates communities by maximizing the intracommunity connectivity (i.e., the connectivity of the nodes included within a community), which simultaneously minimizes the inter-community (i.e., between the communities) connectivity, as is described by the mathematical expression [61]:

$$
\operatorname{maximize}\left[Q \propto\left(m_{\text {within }} \text { communities }-m_{\text {between } \text { communities }}\right)\right]
$$

where $Q$ is the modularity-function [61] and $m$ is the number of network edges (links). The community detection $[61,62]$ is implemented through a greedy algorithm that is applied in two steps [54,61]. At the first step, all nodes in the graph are assigned to different communities. Afterward, the nodes are step-by-step being swept and placed into collectivecommunities if the assignment of a node into an adjacent community increases the weighted modularity function of the original model. At the second step, the collective-communities are replaced by new (super-) nodes, and the process is repeated up to the point that the modularity function cannot increase anymore [61]. Generally, greedy algorithms are sensitive to regional conditions, where the algorithm can be "trapped" in the area of a local-optimum and thus cannot move to a better (global) solution [54,61,62]. Therefore, the generated communities do not a priori describe the (globally) optimum partition of the graph-model into communities but a quite satisfactory division, which ensures that nodes within the communities are well-enough densely connected and well-enough sparsely connected between the communities. According to the comparison provided by the author of [61], amongst 12 in number modularity optimization algorithms, the algorithm of Blondel et al. [62], which is chosen in this paper to run the community detection analysis, belongs to the pair of cases with the smallest order of computational complexity $O(m)$. This property gives this algorithm a privilege to be considered as one of those with optimum performance and, also, its availability to be built-in in the open-source software of [55] makes it a popular choice for community detection analysis. However, the community classification outcome is inevitably dependent on the algorithm that is chosen to perform the analysis, and therefore the results of the community detection cannot be considered unique. For a detailed review about community detection in networks and the optimization methods, the interested reader is referred to the reference work of [61]. Within this context, to manage the restriction due to the greedy architecture of the modularity optimization algorithm, which brings uncertainty both at the step of the algorithm's choice (amongst several others) and at the step of applying the specific algorithm to the network dataset (where the initialization of the algorithm is by default submitted to randomness), we apply some repairing techniques, as follows: First, the community detection analysis is designed to be applied to three correlation-based complex networks (i.e., those converted at $0.01,0.05$, and 0.10 level of significance tables) instead of one, so that the final communities to result by the synthesis of these three aspects incorporating different levels of uncertainty and variability in network connectivity. Secondly, we run the procedure of community detection for a single significance-network several times and we then configure the final community outcome by the mode (i.e., most frequent solution) of all runs. Finally, the results of the analysis in this paper are compared with those obtained in previous work of [9], which applied a grouping to the available seasonal patterns of the Greek prefectures based on the principal components analysis method. Interpreting the results of the comparison in terms 
of regional dynamics and tourism development will provide an evaluation of the proposed in this paper methodology. All these three repairing approaches are expected to reduce the sensitivity of the modularity optimization algorithm due to its greedy architecture.

At the third step of the methodology, the different patterns referring to the modularity communities resulted for $1 \%, 5 \%$, and $10 \%$ levels of significance are jointed to a single classification of seasonal modularity-patterns. This joint-classification takes into account the unique modularity-community patterns of the form $\left(Q_{1 \%}(i), Q_{5 \%}(i), Q_{10 \%}(i)\right)$, where each node (i) belongs to.

At the fourth step, the patterns resulted from the classification of the seasonality modularity-patterns are evaluated by their geographical and socio-economic features that are approximated by a set of 51 variables, as shown in Table A3 in the Appendix A. This analysis is based on the formulation of error-bars expressing $95 \%$ confidence-intervals (CIs), which are computed for the mean values [54,60] of the available socio-economic and geographical (SEG) variables amongst the groups referring to the available seasonal modularity-patterns. When the error-bars do not overlay, the mean values referring to modularity-groups are considered as statistically different, under a $95 \%$ certainty $[9,54,60]$. Thus, comparisons amongst the modularity-groups applied for every SEG variable (Table A2, Appendix A) can reveal which group outperforms (i.e., has a maximum performance) or underperforms (i.e., has a minimum performance) in terms of a single SEG attribute. Within this context, the comparison-results are further tabulated to formulate the total profiles (including seasonality, socio-economic, and geographical information) of the available modularity-groups [9]. This part of the analysis develops linkages between the temporal (as expressed by the time-series patterns of overnight-stays on which the analysis is built), socio-economic, and geographical dimension in the analysis of tourism-seasonality and thus to contribute to the conceptualization of integrating modeling of the complex phenomenon of tourism-seasonality.

The overall approach provides a tool of quantitative analysis that can be proven useful for the scholars and practitioners activating on regional planning, tourism policy, and hospitality management. The findings and the results of the analysis are discussed at the fifth step of the methodology, where an overall assessment and conclusions are formulated.

\section{Results and Discussion}

\subsection{Data Visualization}

The available 51 seasonality-variables of overnight-stays participating in the analysis are first presented to the diagrams shown in Figure 2. This is done for visually detecting possible similarities amongst the seasonality patterns of the 51 Greek prefectures. Each seasonality-variable refers to a Greek region (prefecture) and has 252 monthly records of tourism overnight-stays (i.e., is of length 252), which are recorded for the period from January 1998 to December 2018 [59]. As is evident, almost all available variables have a distinguishable periodicity, which is evident by the oscillating curves of the line-plots. In these patterns, differences in scale (i.e., the oscillation height) and in trend (e.g., some seasonality patterns are described by an increasing trend) can be observed, which are more distinguishable in the metric rather than in the semi-log scale. In particular, in the metric representation, three scale-levels (zones) can be observed in the overlaid line plots of Figure 2, where approximately the first zone ranges from $0-500,000$, the second one from $500,000-2$ million, and the third one from 2-4 million (measured in overnight-stays). These levels correspond to different oscillation heights that express different levels of magnitude in tourism overnight-stays. However, in the semi-log representation, these zones observed in the metric scale do not seem to propose a distinguishable grouping, similarly to the metric case. Instead, in the semi-log scale, one concentration of "noisy" (i.e., not following clear periodical) patterns can be observed at the range of 10-20,000, another cluster of distinguishable periodical patterns can be observed at the range of 100-1 million, and a final one at the range of 100,000-3 million (all expressing overnight-stays). 

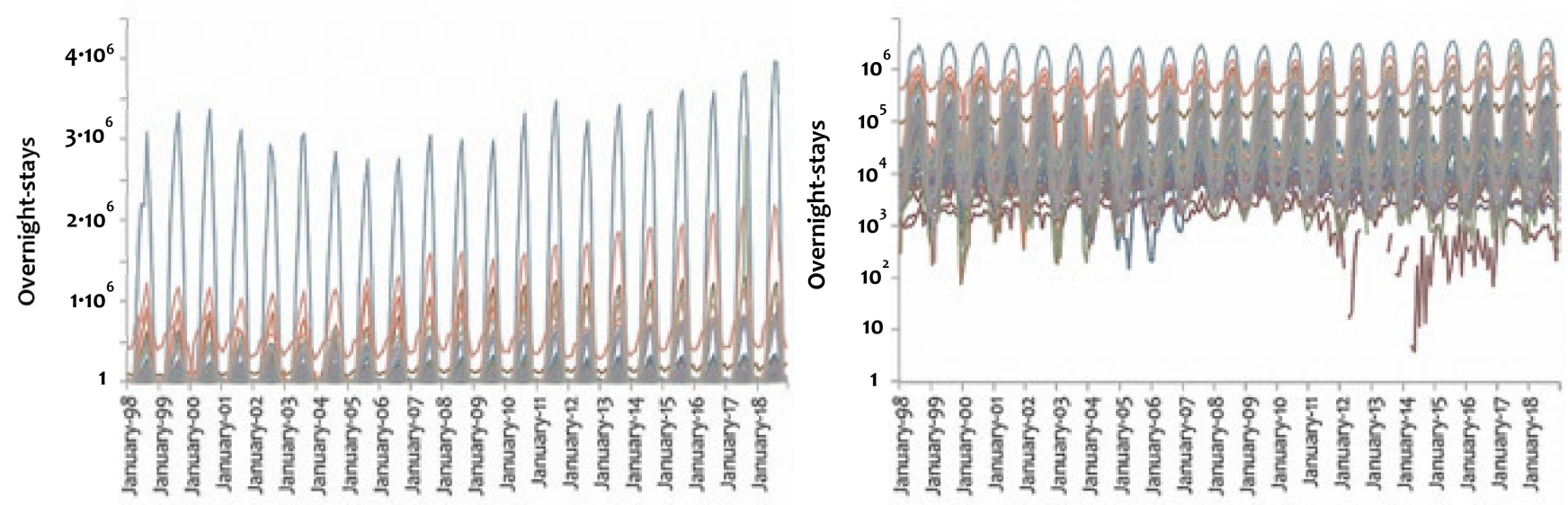

Figure 2. Line-plots showing the time-series patterns of the available 51 seasonality-variables, which are shown in (left) metric and (right) semi-log scale. Each case (seasonality-variable) expresses a seasonality pattern of tourism overnight-stays (shown at the y-axis) that corresponds to one of the 51 prefectures in Greece. Seasonality-variables are of length 252, i.e., including 252 monthly records from January 1998 to December 2018. The available data were granted upon request by the Hellenic Statistical Authority [59] to be used under an exclusive license, for this study.

The previous visual examination of the available data's time-series curves indicates that pattern recognition on data that are jointly submitted to the temporal and geographical configuration is a task of high complexity, where supervision based on intuition can be easily lost, especially on big datasets. Within this context, this paper applies a multilevel approach based on correlation and complex network analysis to jointly manage the temporal and spatial information describing the available dataset. This multi-level approach deals with complexity by integrating linear and non-linear methods and aims to contribute to pattern recognition in seasonality and generally in tourism research.

\subsection{Correlation Analysis}

In the second step of the analysis, the seasonality-variables participate in a correlation analysis to detect linear relations between the possible variable pairs. The results of the analysis are shown in Figure 3, where the correlation tables for each level of significance (i.e., $1 \%, 5 \%$, and $10 \%$ ) are illustrated in heat-maps. In all cases of significance, the analysis first illustrates a distinguishable sub-table $\{29: 50\} \times\{29: 50\}$ of high positive correlations $(>0.6)$, which is shown as area $A_{1}$ in Figure 3 and is configured by the rows 29:50 and the lines 29:50. This sub-table $\left(A_{1}\right)$ includes the seasonality patterns of the prefectures of Fokida (29), at central Greece, Kerkyra (30), Zakeenthos (31), Kefalonia (32), and Lefkada (33), at the Ionian Sea (west Greece), Achaia (34), Aitoloakarnania (35), and Heleia (36), at west Greece, Arkadia (37), Argolida (38), Korinthia (39), Lakonia (40), and Messenia (41), at the Peloponnese, Attiki (42), which is the metropolitan prefecture of Greece, Lesvos (43), Samos (44), Chios (45), Cyclades (46), and Dodecanese (47), at the Aegean Sea, and Heraklion (48), Lasithi (49), and Rethymno (50), on the island of Crete. As it can be observed in Figure 4, the geographical arrangement of these regions is based on the state of the adjacency (where prefectures are mainly located in central and south Greece), have geographical relevance, and their spatial distribution configures a "U"-shaped pattern. 

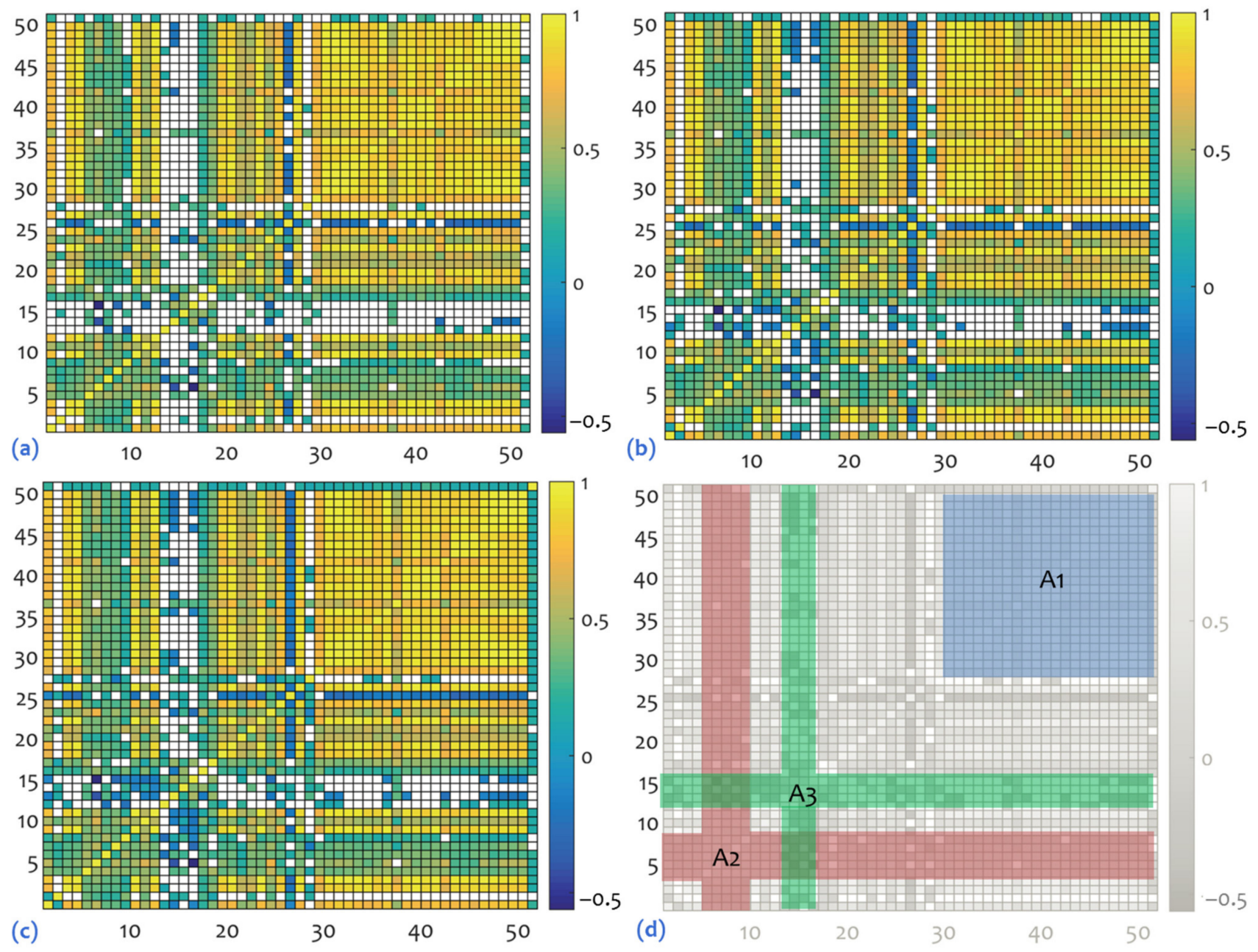

Figure 3. Het-maps showing the results of the correlation analysis applied to the available seasonality-variables (see Table A2 in the Appendix A), where case (a) shows correlations of sig. $=0.01$, (b) of sig. $=0.05$, and (c) of sig. $=0.10$. At these correlation tables, only significant correlations are shown in color. (d) Distinguishable areas $\left(\mathrm{A}_{1}, \mathrm{~A}_{2}\right.$, and $\left.\mathrm{A}_{3}\right)$ of correlated variables in the correlation tables.

Another distinguishable area that can be observed in Figure 3 is the cross-junction area $\mathrm{A}_{2}$, which includes the seasonality patterns of the prefectures of Xanthi (5), Thessaloniki (6), Hmathia (7), Kilkis (8), and Pella (9). All these regions have geographical relevance, as they are located in north-east Greece (Figure 4), as well as tourism-seasonality (functional) relevance, to the extent that they are in their majority positively correlated to all the other seasonality patterns of the Greek regions. A final distinguishable area that can be observed in Figure 3 is the cross-junction area $A_{3}$, which includes the seasonality patterns of the neighbor prefectures of Kozani (13), Grevena (14), Kastoria (15), and Florina (16). These regions have also geographical relevance due to their neighboring location in north Greece (Figure 4) and their functional relevance regards their either negative or insignificant correlations to all other seasonality patterns of the Greek regions. 
(a)

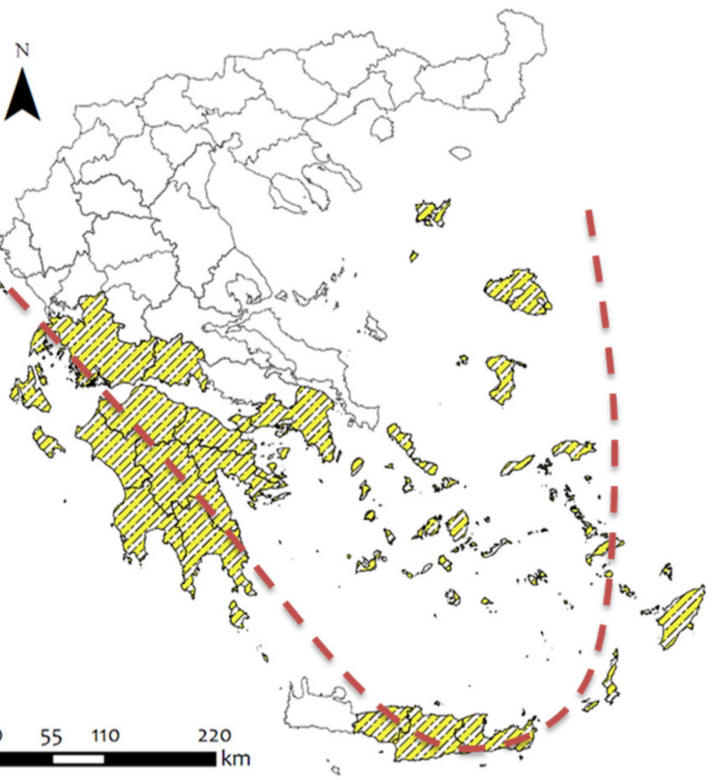

(b)

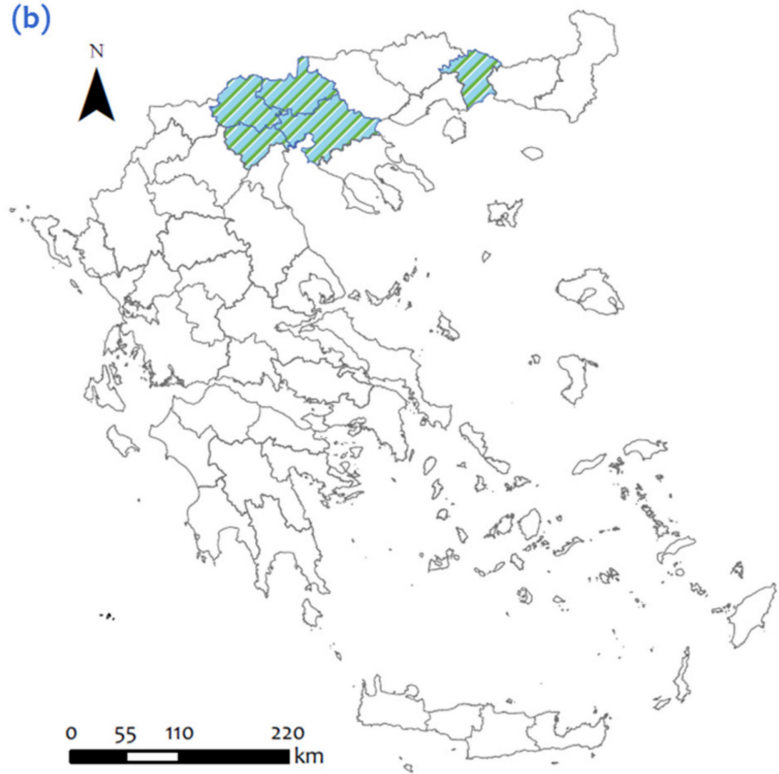

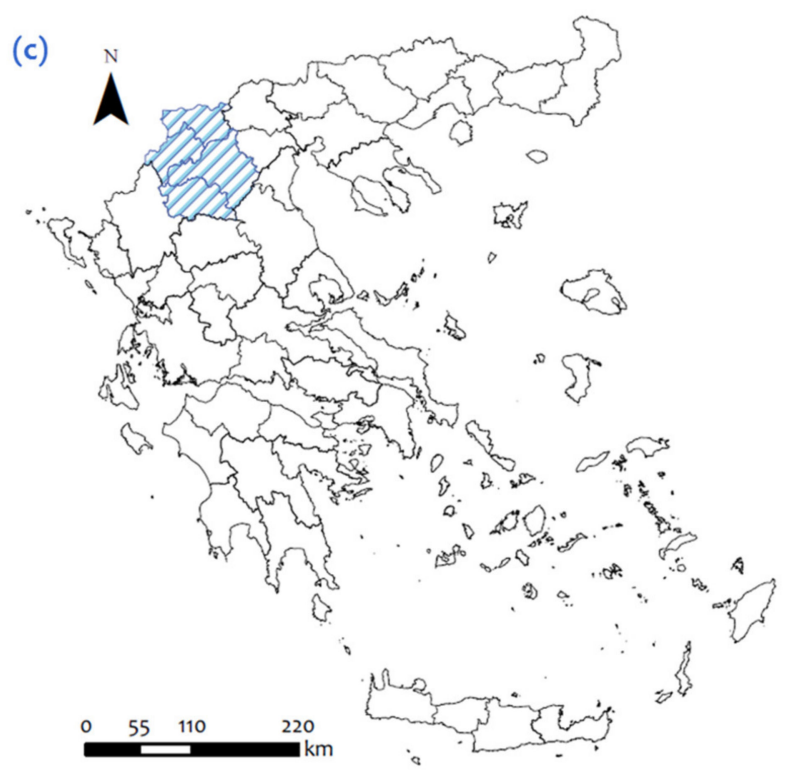

Figure 4. Maps showing the geographical location of the (a) $A_{1},(b) A_{2}$, and (c) $A_{3}$ areas, which are observed in the correlation analysis of Figure 3.

\subsection{Classification of Seasonality Patterns Based on Community Detection}

As being evident by the previous correlation analysis, the temporal dimension of tourism-seasonality can enjoy a spatial conceptualization, which is expressed by the state of neighborhood or adjacency amongst regions with correlated seasonality patterns. However, pattern recognition based exclusively on correlation analysis cannot be that insightful because the geographical patterns that emerged by correlations are quite primary and selective, to the extent that they do not include the total cases of the available population. Within this context, the correlation tables of Figure 3 are converted to graph-models, where a link expresses the value of a significant correlation coefficient between two nodes (prefectures). These graph-models are afterward divided into communities, by applying the modularity optimization algorithm $[54,61,62]$, which generates communities with dense connectivity within and sparse connectivity between them.

The results of the community detection are shown in Figure 5, where regions are 
colored according to the community they belong to. As it can be observed, for the $1 \%$ and $5 \%$ level of significance the graph-models are divided into 3 communities, whereas for the $10 \%$ level of significance the graph-models are divided into 2 communities. Communities for the graph-models of $1 \%$ and $5 \%$ levels of significance include the same number of members, the first one consisting of 13 prefectures, the second one of 6 , and the third (and bigger) one of 32 elements. On the other hand, the first community for the graph-model corresponding to the $10 \%$ level of significance includes 18 members (prefectures), whereas the second one includes 33 elements. As it can be observed, the community grouping corresponding to the case of $10 \%$ significance level results by merging the 13-element and 6-element communities of the $1 \%$ and $5 \%$ significance levels and by shifting one element, the prefecture of Kozani (13), to the 32-element community of the $1 \%$ and $5 \%$ significance levels. This observation implies first that the 13-element and 6-element communities of the $1 \%$ and $5 \%$ significance levels become relevant when uncertainty increases (and thus they are linked in a weak-ties context) and secondly that the prefecture of Kozani (13), shows an interesting outlier performance due to its community shift, suggesting a special case to study.

To evaluate the information provided by the community detection of the available (interregional seasonal correlation) graph-models and to manage the results of the community detection algorithm within a context of repairing their heuristic configuration, a joint assessment is applied to the available modularity classes (communities). In particular, based on the modularity class that each prefecture belongs to, we construct ordered triplets of the form $p=\left(p_{1}, p_{2}, p_{3}\right)$, where the first coordinate $\left(p_{1}, \mathbf{\square}, \mathbf{\square}\right)$ expresses the modularity class for the $1 \%$ level of significance, the second one $\left(\mathbf{\square}, p_{2}, \mathbf{\square}\right)$ for $5 \%$ sig., and the third one $\left(\mathbf{\square}, \mathbf{\square}, p_{3}\right)$ for $10 \%$ significance. Therefore, based on the available ordered triplets $p(i)$, which correspond to the $i=1, \ldots, 51$ modularity (seasonal) classes of the Greek prefectures, four (4) in number unique patterns (clusters) can be distinguished, which are expressed by the triplet-groups $(0,0,1),(1,1,0),(1,1,1)$, and $(2,2,0)$, as is shown in Figure 5. Amongst these patterns (clusters) of modularity classes, the first one configures a sigmoid (" $\mathrm{S}$ "-shaped) spatial pattern (Figure $6 \mathrm{~b}$ ) that consists of the prefectures of Drama (2), Xanthi (5), Thessaloniki (6), Imathia (7), Kilkis (8), Pella (9), Serres (11), Kastoria (15), Ioannina (17), at northern Greece, the prefectures of Karditsa (22), Trikala (24), and Viotia (26), at central Greece, and Chania (51), at the island of Crete. The second one includes a single prefecture, Kozani (13), which is located in north Greece (Figures 5 and 6) and thus it configures a point or dot ("•"-shaped) spatial pattern (Figure 6c) at the central Macedonia region. As is evident, this community consists of the single element with the most unstable connectivity, as denoted by the shifting captured by the intersection consideration of communities between the $1 \%, 5 \%$, and $10 \%$ significance levels. The third cluster configures a linear spatial pattern (Figure 6d) consisting of the prefectures of Grevena (14), Florina (16), at north Greece, Arta (18) and Evrytania (28), at central Greece, and the prefecture of Arkadia (37), at the region of Peloponnesus. 

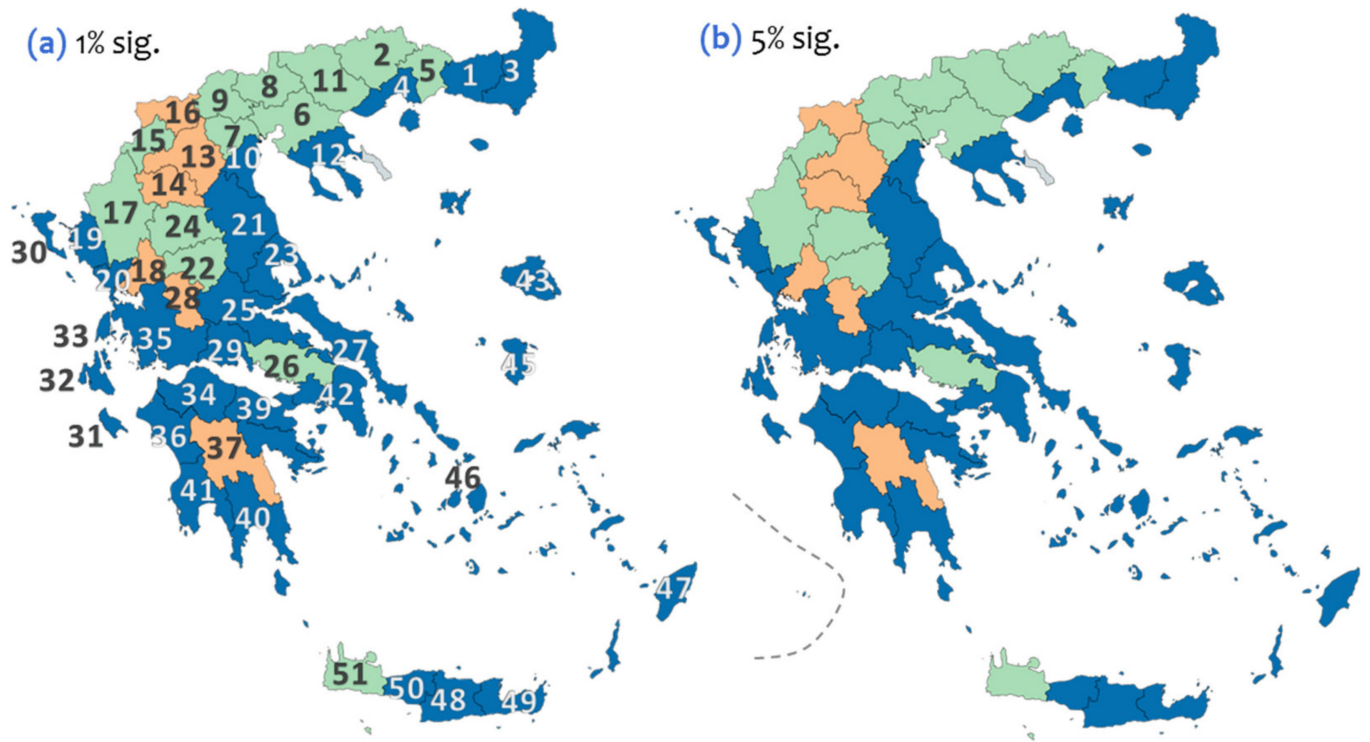

(c) $10 \%$ sig.

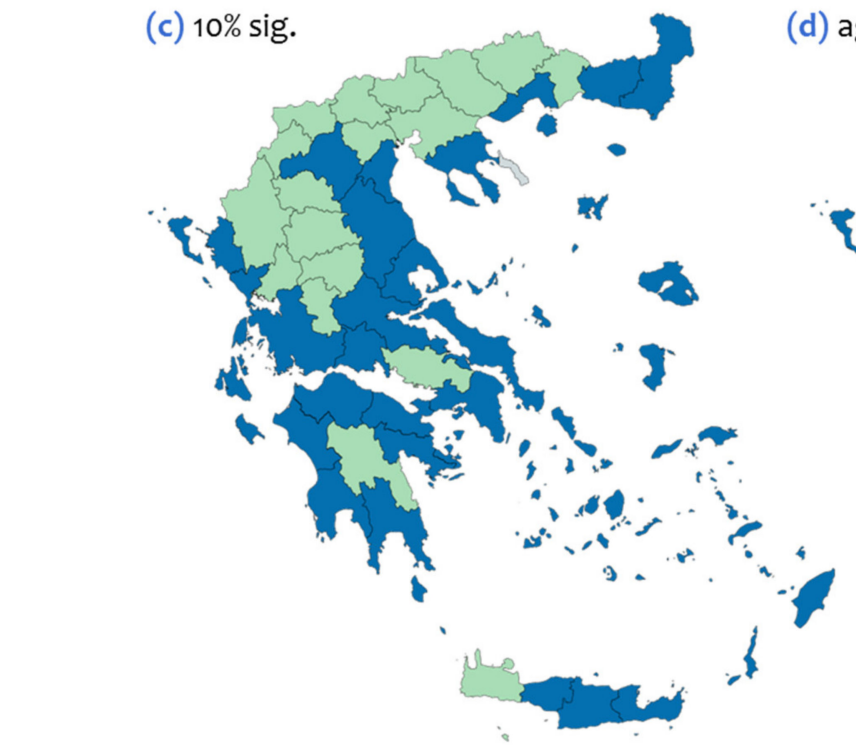

(d) aggregate

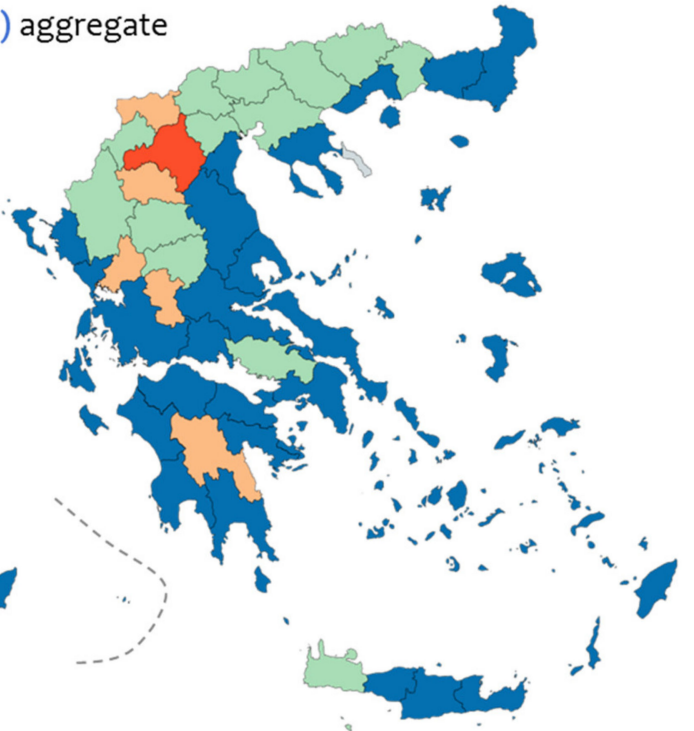

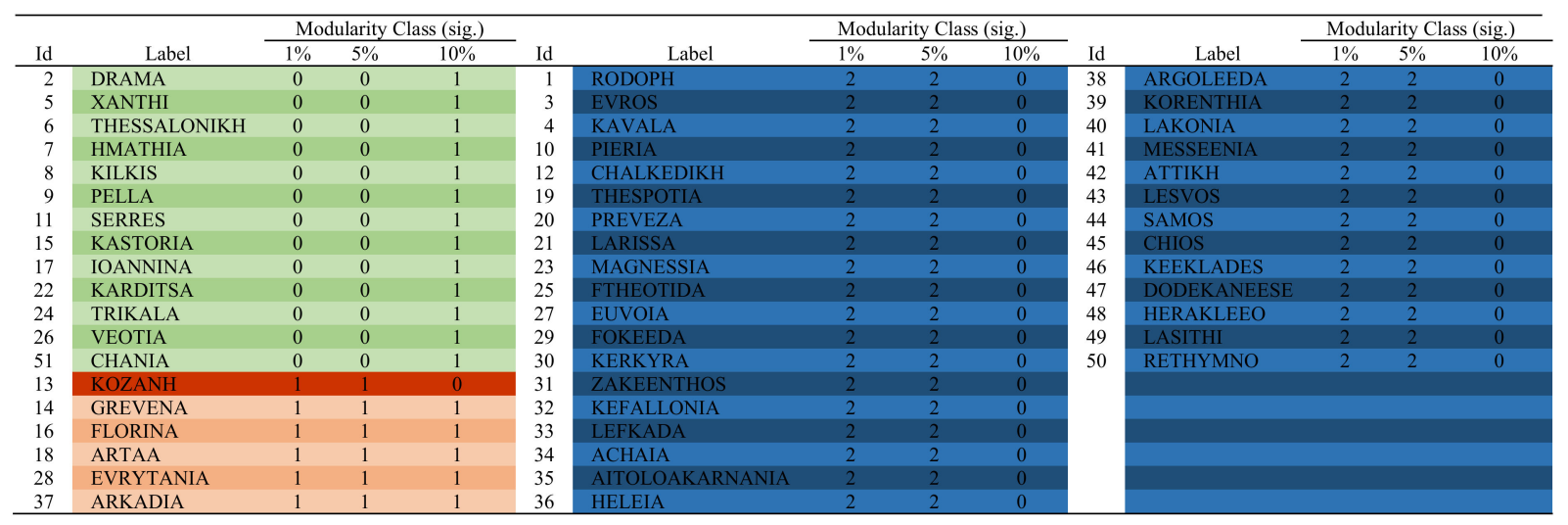

Figure 5. Geographical distribution and tabulation of the seasonality patterns that correspond to the Greek prefectures and are produced by the modularity classification for (a) $1 \%$, (b) $5 \%$, and (c) 10\% levels of significance. Case (d) shows the aggregate patterns including the unique triplets of the $(\mathbf{a}-\mathbf{c})$ modularity classes. Dashed lines illustrate shapes of spatial patterns. 


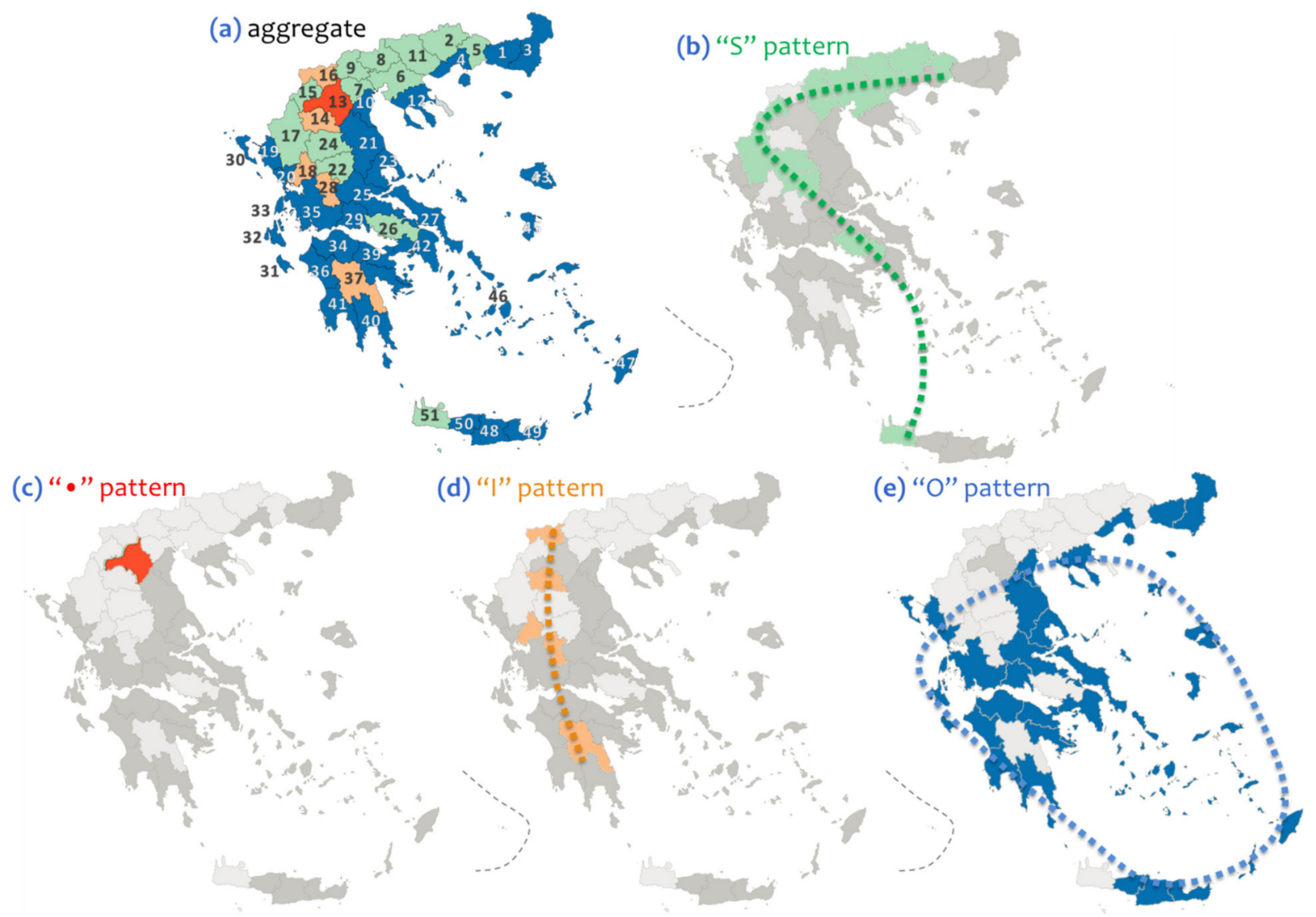

Figure 6. Maps showing the geographical distribution of the available 51 seasonality patterns that are grouped (according to the modularity classification shown in Figure 5) to the modularity (triplet-) groups, as follows: (a) aggregate, including all 4 available groups, (b) $(0,0,1)$, of an "S"-shaped spatial pattern, (c) $(1,1,0)$, of a "dot"-shaped spatial pattern, (d) $(1,1,1)$, of an "I"-shaped spatial pattern, and (e) $(2,2,0)$, of an "O"-shaped spatial pattern.

Finally, the fourth cluster configures a circular ("O"'-shaped) spatial pattern (Figure 6e) that consists of the prefectures of Rodoph (1), Evros (3), Kavala (4), and Chalkedikh (19), at the regions of eastern Macedonia and Thrace, Pieria (10), Thespotia (12), Preveza (21), Aitoloakarnania (35), Kerkyra (30), Zakeenthos (31), Kefallonia (32), and Lefkada (33), at west Greece, Larissa (21), Magnessia (23), Ftheotida (25), Euvoia (27), and Fokeeda (29), at central Greece, Achaia (34), Heleia (36), Argoleeda (38), Korenthia (39), Lakonia (40), and Messeenia (41), at the region of Peloponnesus, the metropolitan region of Attiki (42), Lesvos (43), Samos (44), Chios (45), Keeklades (46), and Dodekaneese (47), at the Aegean Sea, and Herakleeo (48), Lasithi (49), Rethymno (50), at the island of Crete.

According to the community detection analysis, the modularity communities can relate the temporal with the spatial dimension of tourism-seasonality within a more perplexing context than this shown in Figure 4, where the modularity groups $\left(p_{1}, p_{2}, p_{3}\right)$ that were generated configure diverse but also distinguishable spatial patterns in the geographical map of Figure 6. Within this framework of complexity, to further decompose and examine the multiplex information included in these modularity groups, we illustrate the lineplots of the overnight stay time-series per modularity group, as is shown in Figure 7. As it can be observed, modularity groups $(0,0,1)$ and cluster $(2,2,0)$ include seasonality patterns with more discrete periodical patterns, whereas groups $(1,1,0)$ and $(1,1,1)$ are described as more noisy patterns. In particular, the first modularity group $(0,0,1)$, which corresponds to the "S"-shaped spatial pattern of Figure 6, includes cases that are described by a periodic pattern with an increasing trend. The case included in the second modularity group $(1,1,0)$, which refers to the "dot"-shaped spatial pattern of Figure 6, is described 
by a noisy seasonal pattern with a decreasing trend, where linearity is more obvious in the time-series curve than periodicity. Also, the third modularity group $(1,1,1)$, which corresponds to the "I"-shaped spatial pattern of Figure 6, includes cases that are described by a noisy periodical pattern that configures (on average) a bell-shaped curve with its convex part defined at the period 2003-2012. Finally, the fourth (and larger) modularity group $(2,2,0)$, which corresponds to the "O" $\mathrm{O}$-shaped spatial pattern of Figure 6, includes cases that are described by an approximately cyclical pattern (i.e., a periodical with the same oscillation amplitude) that configures (on average) a U-shaped curve with its concave part also defined at the period 2003-2012. Overall, this analysis allows claiming that the four available modularity groups have, along with their spatial patterns, distinguishable seasonality patterns, on average.
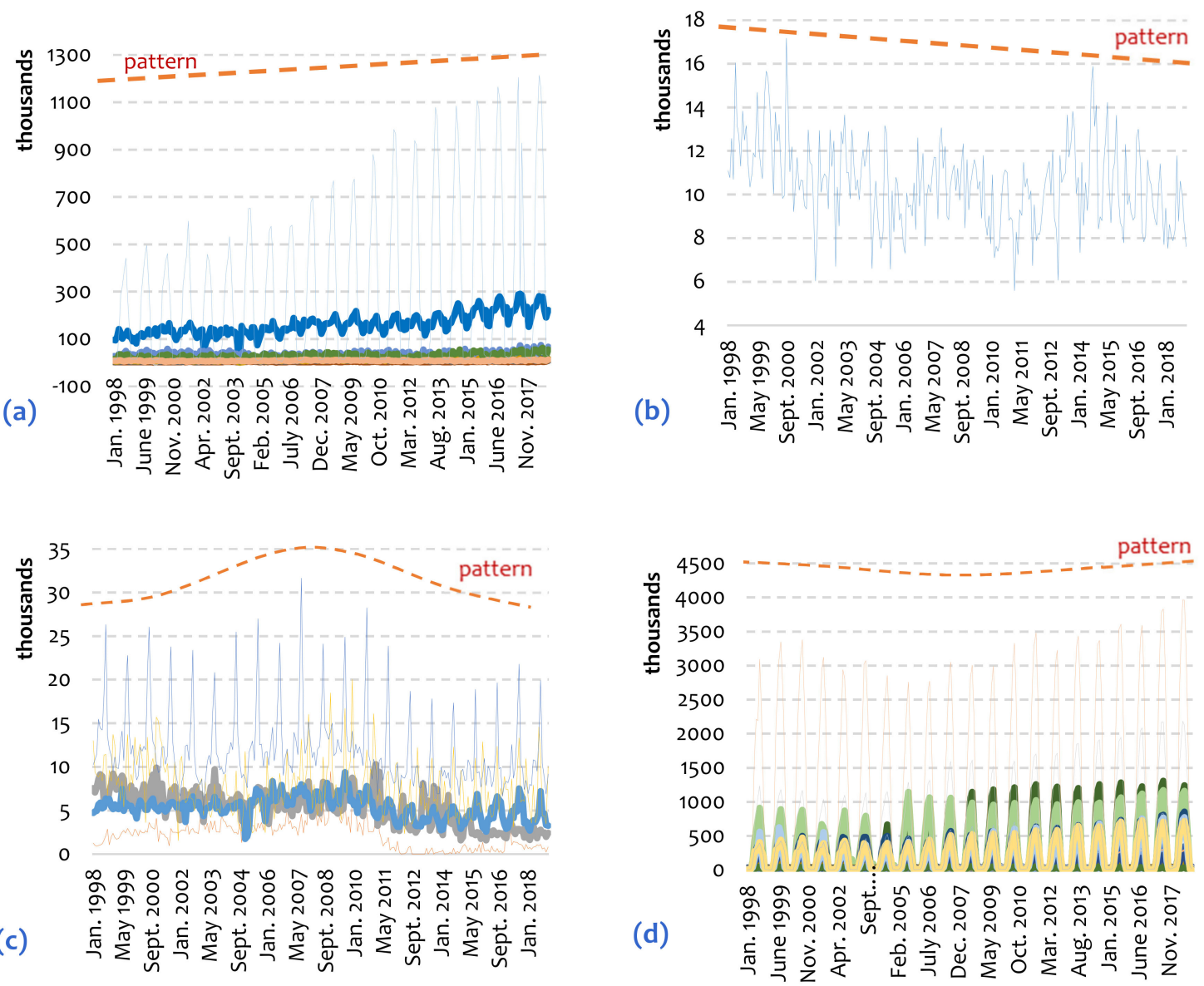

Figure 7. Line plots with the time-series of the available 51 seasonality patterns that are grouped (according to the modularity classification shown in Figure 6$)$ to the triplet-groups: $(\mathbf{a})(0,0,1)$ of the "S"-shaped spatial pattern, (b) $(1,1,0)$ of the "dot"-shaped spatial pattern, (c) $(1,1,1)$ of the "I"-shaped spatial pattern, and (d) $(2,2,0)$ of the "O"-shaped spatial pattern.

To detect differences at the scale of seasonality amongst the available modularity groups, we apply further analysis based on error-bars of confidence intervals (CIs) [54,60]. In particular, we construct $95 \%$ CIs for the mean values of the Gini coefficient $[9,37]$ and the RSI (Relative Seasonal Index) [14,36], which are composite indicators capturing aspects of seasonality on a set of data. The results are shown in Figure 8, where it can be observed that the modularity group $(2,2,0)$, the one with the "O"-shaped spatial pattern, has on average the maximum score of seasonality, which is statistically different than these of all the other groups. On the other hand, the modularity group $(1,1,0)$, described by the "dot"-shaped spatial pattern, has on average the minimum score of seasonality, which is statistically different than this of $(1,1,0)$ and $(2,2,0)$ groups. However, no statistical difference can be detected between the $(0,0,1)$ and $(1,1,1)$ groups, implying that their seasonality patterns lie 
on the same scale level. Overall, this analysis highlights that community detection resulted from the modularity optimization algorithm sufficed to configure communities separating the minimum and maximum performance in tourism-seasonality, as it can be captured by the Gini coefficient and the Relative Seasonal Index.
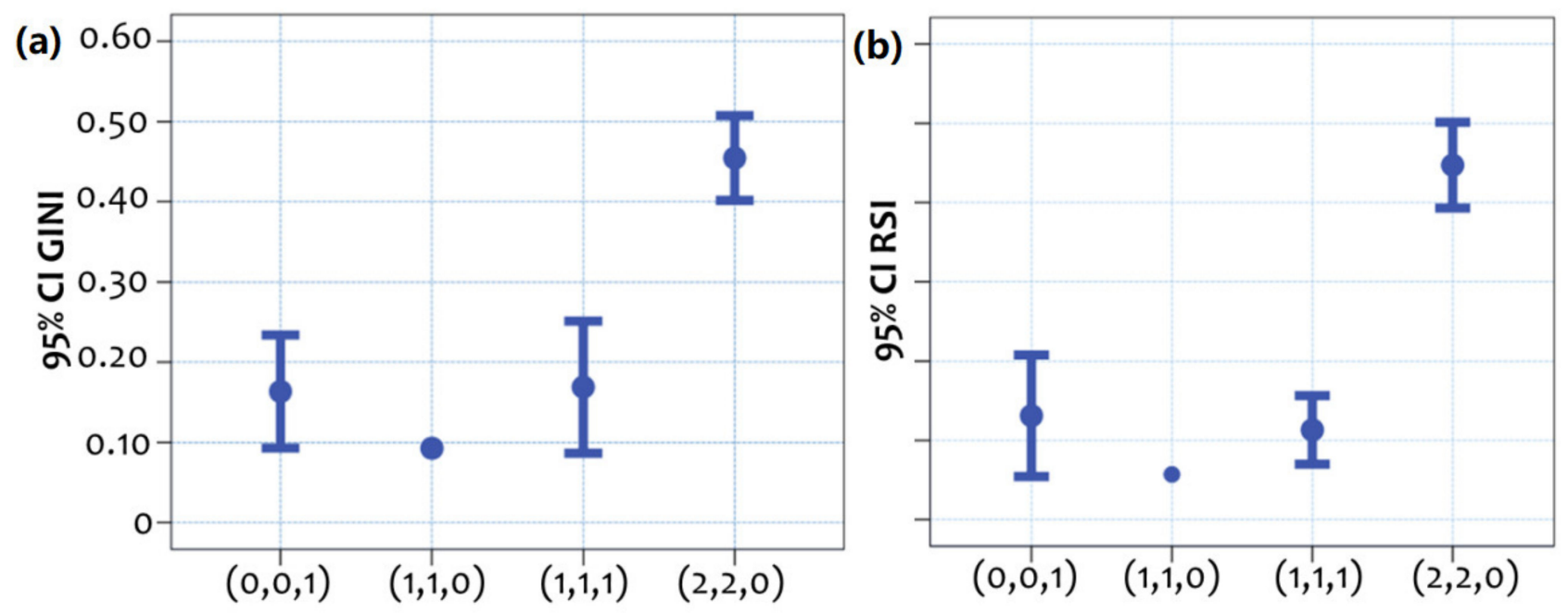

Figure 8. Error-bar plots representing 95\% confidence intervals (95\%CIs) for the mean values of (a) the Gini coefficient and (b) the RSI (Relative Seasonal Index).

\subsection{Socio-Economic Determination of the Modularity Seasonal Groups}

In the fourth step of the methodology, the available modularity groups are interpreted in terms of their geographical and socio-economic information. To do so, the analysis builds on comparisons amongst error-bars of $95 \%$ confidence intervals, which are computed for a set of 51 (in number) available variables that are divided into thematic categories (geographical, seasonality, transport, demographic, productivity, tourism, environmental, and cultural), as is shown in the Appendix A (Table A3). Based on the error-bars comparisons, the statistically significant minimum and maximum performances per variable are tabulated and shown in the Appendix A (Table A4). According to this analysis, the prefectures belonging to the modularity group $(0,0,1)$ have high urbanization, winter tourism activity specialization, the capacity of "Natura" (i.e., biodiversity protected) areas, and the capacity of woodland parks. On the other hand, the prefectures included in this group have not rich geomorphological configuration, relatively low seasonality performance, and a small number of ports, are not specialized in the secondary sector, not equipped with industrial areas, and have a small number of camping areas and beaches. The prefecture of Kozani (13), which configures the modularity group $(1,1,0)$, is located in northwest Greece, is a mainland prefecture with rich geomorphological configuration, high income, tourism specialization, and specialization in winter tourism activities.

On the other hand, this single-member group has low seasonality, tourism capacity in terms of accommodation, and level of environmental and cultural resources. The prefectures belonging to the modularity group $(1,1,1)$, which are mainly located on the mainland, are cases with high urbanization, but with low geomorphological configuration, seasonality, sea geomorphology, and tourism profile, as well as demographic and income background. Finally, the prefectures belonging to the modularity group $(2,2,0)$ are mainly located in southeast Greece, where their sea geomorphologic configuration is dominant. Prefectures of this group have high seasonality, urbanization, primary and tertiary sector specialization, tourism profile, and environmental and cultural resources. On the contrary, cases of this modularity group have low mountainous geomorphology. All previous interpretation is tabulated in Table 1, where the socio-economic and geographical profiles of the modularity groups are illustrated. 
Table 1. The semiology of the modularity groups (see Figure 5) resulted from the analysis.

\begin{tabular}{|c|c|c|}
\hline \multirow{2}{*}{$\begin{array}{l}\text { Modularity } \\
\text { Groups (Size) }\end{array}$} & \multicolumn{2}{|c|}{ Socio-Economic and Geographical Semiology } \\
\hline & $\operatorname{MAX}^{(a)}$ & $\mathrm{MIN}^{(\mathrm{b})}$ \\
\hline $\begin{array}{l}\text { Group }(\mathbf{0 , 0 , 1 )} \\
(13 \text { prefectures })\end{array}$ & $\begin{array}{l}\text { Northern and eastern location; urbanization; } \\
\text { specialization in winter tourism activities; } \\
\text { environmental wealth. }\end{array}$ & Area; seasonality; ports; camping; beaches. \\
\hline $\begin{array}{l}\text { Group }(\mathbf{1}, \mathbf{1}, \mathbf{0}) \\
\text { (1 prefecture) }\end{array}$ & $\begin{array}{l}\text { Northern and west location; rich geomorphological } \\
\text { configuration; mainland geomorphology; rich rail and } \\
\text { airport configuration; high secondary sector } \\
\text { specialization; high mountainous activities. }\end{array}$ & $\begin{array}{l}\text { Coastal or island area; seasonality; poor road density } \\
\text { and roads; low primary and tertiary sector } \\
\text { specialization; low tourism profile; low environmental } \\
\text { wealth, low cultural resources profile. }\end{array}$ \\
\hline $\begin{array}{l}\text { Group (1,1,1) } \\
\text { (5 prefectures) }\end{array}$ & $\begin{array}{l}\text { Mainland geomorphology; urbanization; high tertiary } \\
\text { sector specialization; high environmental wealth. }\end{array}$ & $\begin{array}{l}\text { Coastal or island area; poor geomorphological } \\
\text { configuration; seasonality; poor ports and airports } \\
\text { configuration; population and human capital; low } \\
\text { income; low secondary sector specialization; low } \\
\text { tourism profile; low beach environment; low cultural } \\
\text { resources profile. }\end{array}$ \\
\hline
\end{tabular}

Southern and eastern location; coastal or island area, high seasonality; rich road density and ports Group $(2,2,0) \quad$ configuration; high urbanization; high primary and (32 prefectures) tertiary sector specialization; high tourism profile; high environmental quality; high capacity of cultural resources.
Poor geomorphological configuration; poor rail configuration; low secondary sector specialization; low mountainous activities.

(a) as defined by the max values of Table A4 (see Appendix A). ${ }^{\text {(b) }}$ as defined by the min values of Table A4 (see Appendix A).

As it can be observed from Table 1 , the first modularity group $(0,0,1)$, which is a group with a sigmoid geographical distribution and a seasonal pattern described by periodicity and an increasing trend, is a group where its relatively low seasonality pattern seems to be driven by forces related to winter tourism activities and MICE tourism (i.e., meetings, incentives, conferencing, exhibitions) attractions due to urbanization configuration. The second modularity group $(1,1,0)$, concerning a single-prefecture group described by a noisy low seasonality pattern with a decreasing trend, has its seasonality related to the mainland geomorphology, high rail, and airport integration (but poor road density), and a mountainous tourism specialization. The third modularity group $(1,1,1)$, which configures a linear geographical pattern and has a noisy periodical pattern with a bell-shaped curve running a stage of decline, is a group owing to its seasonal pattern to high environmental wealth and forces related to tertiary specialization and low transport integration and tourism profile. Finally, the fourth modularity group $(2,2,0)$, which is the largest group described by a circular geographical configuration and an approximately cyclical pattern of seasonality, has its seasonality related to its rich sea geomorphology, environmental, and cultural wealth, as long as transport integration. This group is mainly related to the $3 S$ (i.e., sea, sun, and sand) tourism activities that are the dominant model describing the nature of the tourism product in Greece.

\section{Further Analysis and Overall Assessment}

To further evaluate the effectiveness of the overall correlation-based complex network analysis applied in this paper, we compare the results of the modularity grouping with those presented in a previous work [9] of the authors, which were produced by applying a Principal Components Analysis (PCA) method to the same overnight-stays database. This comparative approach, on the one hand, is expected to provide insights into the uncertainty due to the modularity optimization algorithm and, on the other hand, to evaluate the effectiveness of the method proposed in this paper. In particular, the authors of [9] applied a PCA to the same set of seasonality-variables (see Table A2 Appendix A) by choosing the covariance matrix extraction and the Varimax rotation methods. The PCA resulted in seven (7) principal components explaining a high percentage $(84.86 \%)$ of the total variance. 
Provided that the PCA's component matrix includes component loadings (which are defined by correlations) between the principal components and all the available variables, further min-max filtering was applied in this approach to singularly assign one variable in a unique PCA component. The PCA yielded two groupings of the available 51 Greek prefectures, where the first one (which was generated by considering only the maximum -M- component loadings per variable) consisted of five (5) groups including 38 (PCM\#1), 7 (PCM\#2), 4 (PCM\#3), 1 (PCM\#4), and 1 (PCM\#5) cases (prefectures) respectively, while the second one (which was generated by considering only the minimum -m- component loadings per variable) consisted of seven (7) groups including 1 (PC\#1), 7 (PC\#2), 13 (PC\#3), 14 (PC\#4), 8 (PC\#5), 5 (PC\#6), and 3 (PC\#7) cases, respectively. The labeling of both PCA groupings was according to the ranking of the principal components resulted from their eigenvalues shown in the scree plot.

Within this context, Table 2 is constructed for the comparison and measurement of the relevance between the modularity grouping (MOD) applied to this paper with the PCA grouping applied in the previous paper [9] of the same authors. This comparison table has a multilayer block-structure consisting of a window (block) named "Intersection Frequencies" that displays the set-theoretic intersections $P C \# i \cap M O D \# j$ between the $i$-th PCA and $j$-th modularity groups, two other blocks named "Relevance to PCA/MOD Groups" that display the percentage (\%) of coverage that the PCA/MOD groups have for each intersection, and a final window displaying relevance differences that imply which (PCA/MOD) group is more relevant (dominant) to each intersection.

As it can be observed, first the PCM grouping (which is generated by the maxfiltering of the PCA component loadings) includes 4 intersections equal to entire PCM

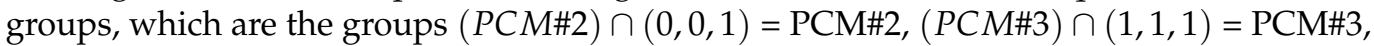
$(P C M \# 4) \cap(1,1,0)=\mathrm{PCM} \# 4$, and $(P C M \# 5) \cap(0,0,1)=\mathrm{PCM} \# 5$ consisting of 13 prefectures in total. Next, the PCm grouping (which is generated by the min-filtering of the PCA component loadings) does not include intersections equal to entire PCm groups $P C M \# i \cap M O D \# j \neq P C M \# i$. Finally, the MOD grouping applied to this paper includes 2 intersections equal to entire MOD groups, namely $(P C M \# 1) \cap(2,2,0)=(2,2,0)$ and $(P C M \# 4) \cap(1,1,0)=(1,1,0)$, which include 33 cases in total. This observation implies a better performance of the modularity than the PCA grouping because the intersections that equal to entire MOD groups are bigger in the total group size.

Next, according to the relevance-assessment shown in Table 2, the 6 cases (prefec-

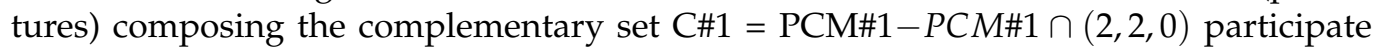
in an amount of $38.5 \%$ in the configuration of the modularity group $(0,0,1), 20 \%$ in the configuration of the modularity group $(1,1,1)$, and $13.2+2.6=15.8 \%$ in the configuration of the PCM\#1 group. These shares imply that set $\mathrm{C \# 1}$ is more relevant in the configuration of the modularity than the PCA groups and therefore they can provide another indication of better performance of the MOD than the PCA grouping.

Finally, as is evident by the block-structure of Table 2, the PCA grouping is by default described by a higher level of complexity than the MOD grouping because of the dual (min-filtering and max-filtering) structure describing the PCA groups. Therefore, in terms of resolution of the grouping outcome, the modularity grouping can be considered more reliable than the PCA's because it results in a singular instead of dual grouping outcome. Moreover, amongst the two PCM and PCm groups, the modularity grouping appears more relevant to the max-filtering (PCM) than to the min-filtering ( $\mathrm{PCm}$ ) outcome. This relevance is obvious in terms of groups' number (i.e., the number of MOD groups is closer to the number of PCM than PCm groups), but it can be further supported by the rank-size distribution of the groups, which follows a power-law pattern in the case of PCM and MOD groupings whereas a Gaussian-like for the PCm grouping. 


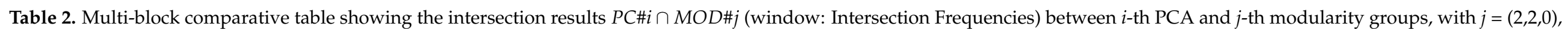

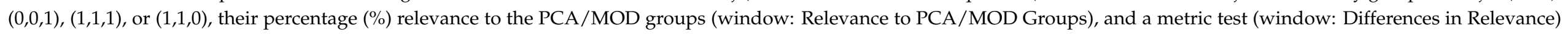
implying which (PCA/MOD) group is dominant for each intersection.

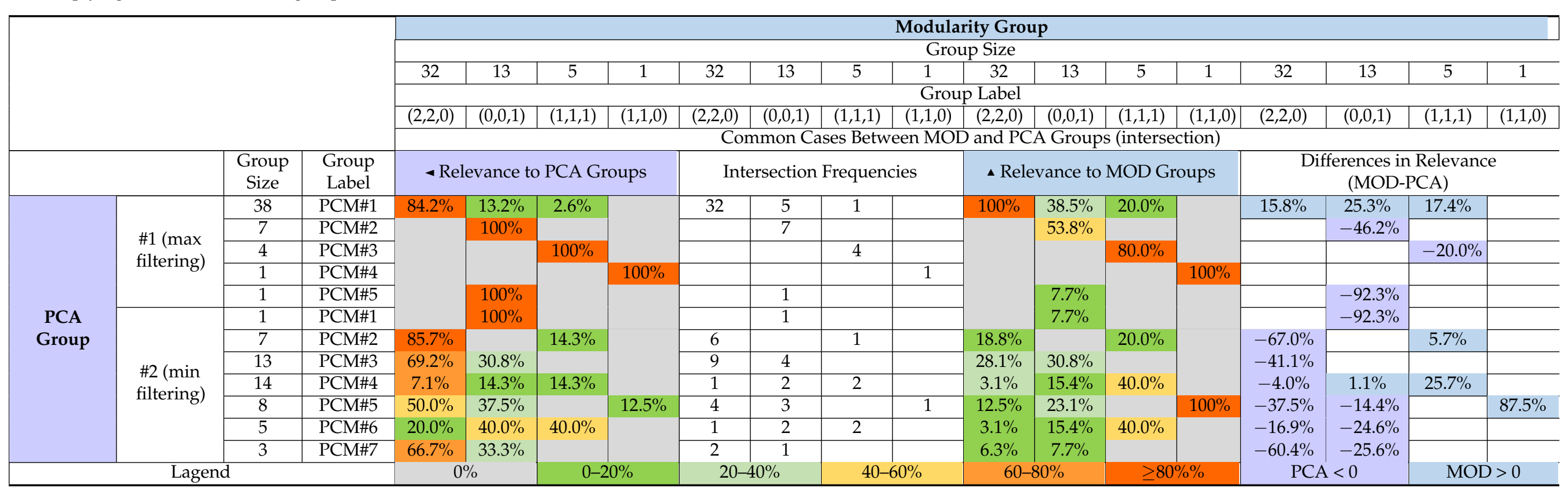


In spatial terms, Figures 9 and 10 show the geographical distribution of the maxfiltering $(\mathrm{PCM})$ and min-filtering $(\mathrm{PCm})$ groupings resulted from the Principal Components Analysis being available in the previous work of [9]. As it can be observed in Figure 9, group PCM\#1 configures an "O"-shaped pattern, $\mathrm{PCM} \# 2$ a " $\mathrm{U}$ "-shaped pattern, $\mathrm{PCM} \# 3$ an "I"-shaped, and PCM\#4 and PCM\#5 "dot"-shaped patterns. On the other hand, group PCm\#1 configures a "dot"-shaped pattern, PCM\#2 an "O"-shaped pattern, PCM\#3 and PCM\#4 "U"-shaped patterns, PCM\#5 an "S"-shaped pattern, and PCM\#6 and PCM\#7 "I"-shaped patterns, as is shown in Figure 10. Between the PCM and PCm groupings, the geographical distribution of the former appears more relevant to this of the MOD grouping, whereas PCm appears less relevant and messier. On the one hand, this relevance (that is observed between the spatial patterns of the PCM and MOD groupings) is consistent with the quantification shown in Table 2 and generally implies that different clustering techniques can lead to converging outcomes when the system being examined is described by considerable underlying causality. On the other hand, measurable differences that are captured between different grouping outcomes can quantify the reliability of each clustering technique. Within this context, the modularity grouping proposed in this paper appears overall more reliable than the PCA, in terms of grouping singularity, size, and configuration. This added value can be due to the complex-network approach applied in this paper, which incorporates topological information related to connectivity of interconnected data instead of just considering their scale and variability.

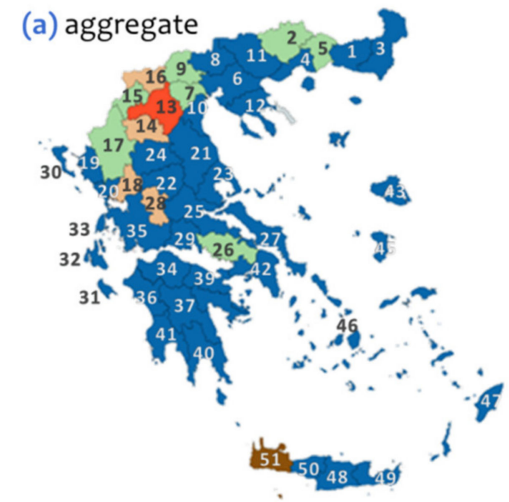

(d) "I" pattern

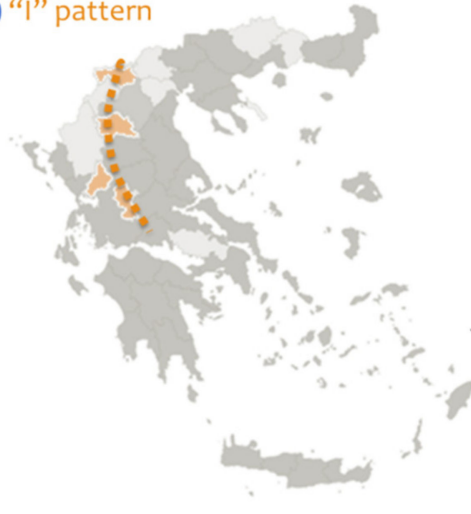

(b) "O" pattern

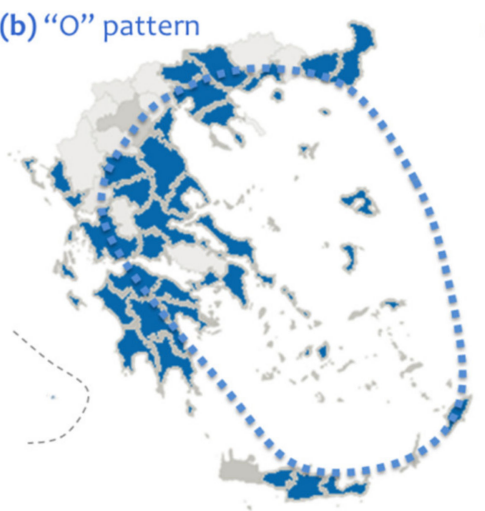

(e) “•" pattern

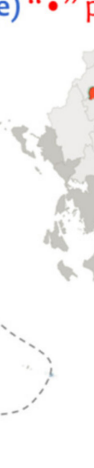

(c) "U" pattern

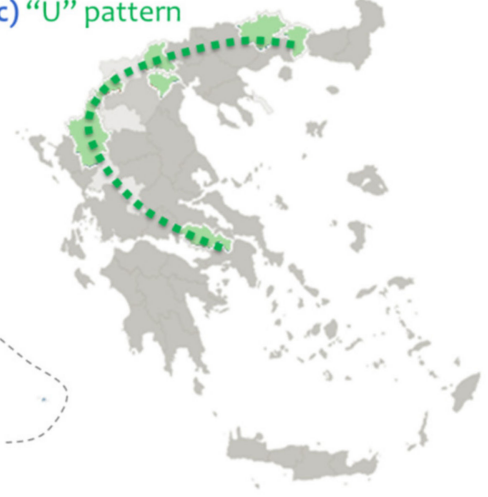

(f) “•” pattern

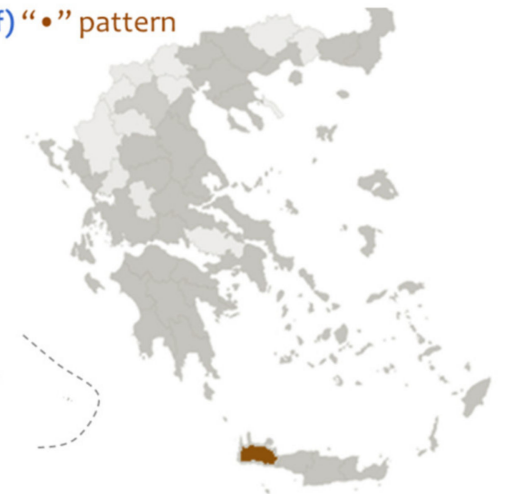

Figure 9. Maps showing the geographical distribution of the Principal Components Analysis max-filtering groups (PCM) that are computed in the paper of [9], where (a) is the aggregate group, including all 5 available PCM groups, (b) is the $\mathrm{PCM \# 1}$ group of an "O"-shaped spatial pattern, (c) is the PCM\#2 group of a " $\mathrm{U}$ "-shaped spatial pattern, $(\mathbf{d})$ is the PCM\#3 group of an "I"-shaped spatial pattern, (e) is the PCM\#4 group of a "dot"-shaped spatial pattern, and (f) is the PCM\#5 group of a "dot"-shaped spatial pattern. 

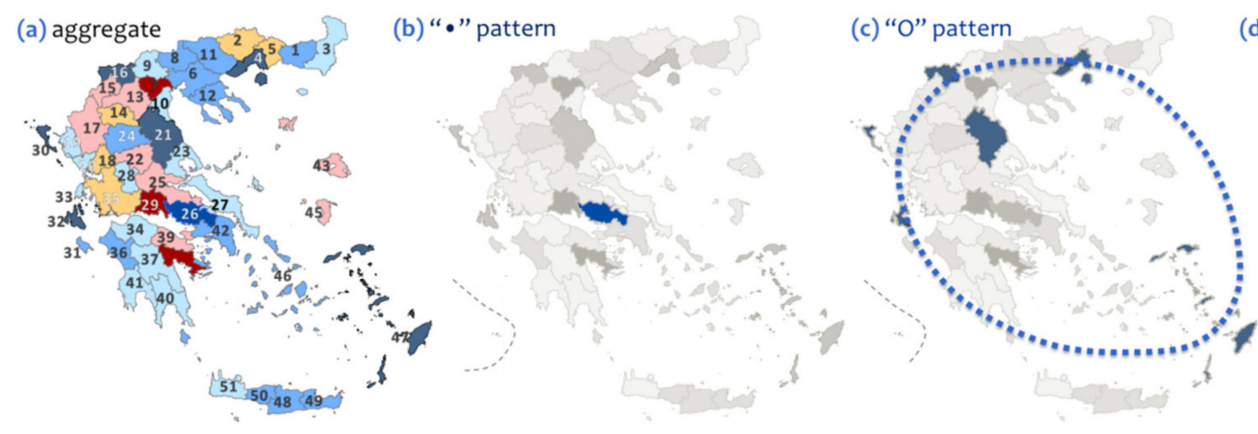

(d) "U" pattern
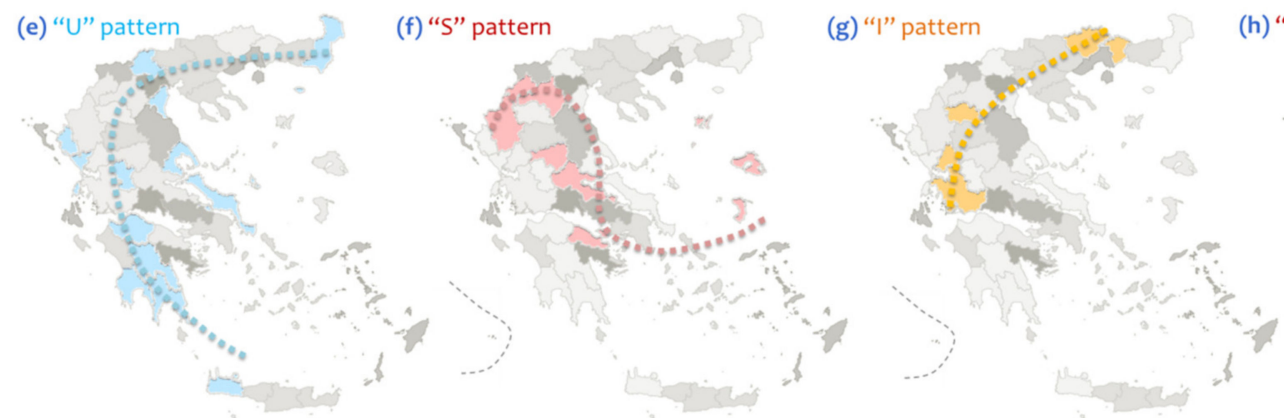

(h) “l” pattern
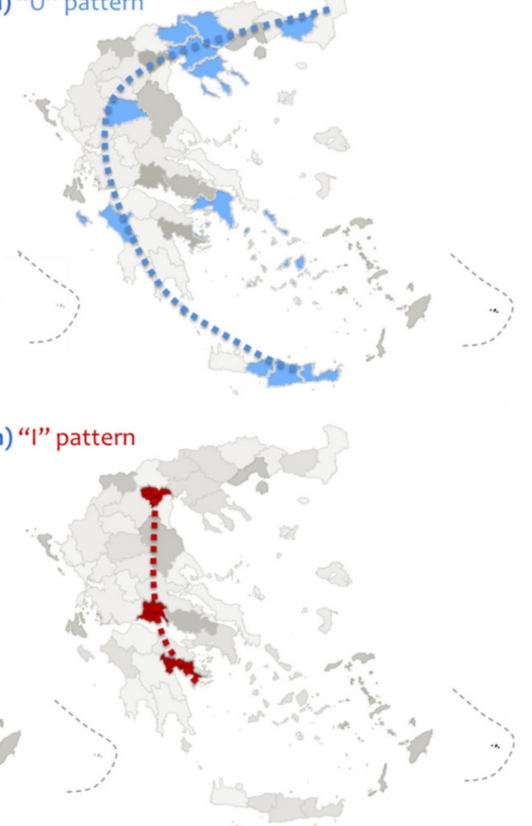

Figure 10. Maps showing the geographical distribution of the Principal Components Analysis min-filtering groups (PCm) that are computed in the paper of [9], where (a) is the aggregate group, including all 7 available PCm groups, (b) is the PCm\#1 groups of a "dot"-shaped spatial pattern, (c) is the PCA\#2 group of an "O"-shaped spatial pattern, (d) and (e) are the PCA\#3 and PCA\#4 groups of a "U"-shaped spatial patterns, (f) is the PCA\#5 group of an "S"-shaped spatial pattern, and $(\mathbf{g})$ and $(\mathbf{h})$ are the PCA\#6 and PCA\#7 groups of an "I"-shaped spatial patterns.

However, despite these indications of better performance describing the proposed complex-network-based method in comparison to the PCA grouping, a study that builds on clustering, numerical analysis, and heuristic optimization is inevitably submitted to uncertainty due to the modeling choices and computational constraints. In this paper, the number and the configuration of the generated groups were a result of optimization based on a heuristic algorithm, where iteration suggests a prime repairing technique to consider and manage the variability of results. Towards this direction, several avenues of further research can emerge. One may concern examining the convergence of the results due to iterations implemented within a single grouping method, such as the modularity grouping proposed in this paper. In this avenue, the characteristic parameters (e.g., degrees of freedom, variability, scale, etc.) describing the dataset and those describing the grouping outcome (e.g., number, scale, and variability of groups) can be correlated. Another avenue is examining the convergence between different grouping methods, similarly to the comparisons between the MOD and PCA groupings applied in this paper. In this approach, the variability observed in the grouping results (e.g., in the number and size of groups) should be evaluated in the light of the computational mechanism describing each method, which can be based either on variance, or distance, or scale, or positioning, or similar relevance-like conceptualization. Despite such computational-based approaches, avenues for further research can also emerge at the level of implementation, and particularly they can concern the management of the resulting groups in terms of tourism policy and regional development. For instance, an effective clustering on temporal patterns of tourism demand can be insightful for the tourism policy-makers to better distribute the national budget of tourism development across the regions based on their relevant profiles or to develop more efficient tourism developmental strategies that would be customized to the tourism profile of each group. Overall, the limitations that are applicable in this study can excellently suggest avenues of further research that can contribute to the integration of the spatial, temporal, and socioeconomic aspects in tourism research. 


\section{Conclusions}

This paper developed a multilevel methodology for analyzing time (temporal) patterns of tourism-seasonality and for grouping them into regional classes and therefore to configure distinguishable seasonality profiles facilitating tourism policy and development. The proposed method was built on a multilevel pattern recognition incorporating time-series assessment, correlation (linear assessment), and complex network analysis (non-linear assessment) to deal jointly with the temporal and spatial dimension of tourism-seasonality and to interpret the results of the analysis in socio-economic terms. The available data were registrations of overnight-stays for the years from 1998 up to 2018, which were provided by the Hellenic Statistical Authority [59] under an exclusive license. The analysis revealed four groups of seasonality, which were configured by a connectivity conceptualization based on the modularity optimization algorithm, where each group showed to be described by distinguishable spatial and seasonality patterns and to enjoy distinct socio-economic semiology. In particular, the first modularity group has a relatively low seasonality, with a pattern described on average by periodicity and an increasing trend, and a sigmoid geographical distribution. The seasonal pattern of this group is driven by forces related to winter tourism activities and MICE tourism attractions. The second, single-prefecture, modularity group has the lowest seasonality and is described by a noisy pattern with a decreasing trend, where its seasonality is related to rich geomorphological mountainous configuration and a mountainous tourism specialization. The third modularity group has a relatively low seasonality with a pattern described by a linear geographical distribution and on average by a noisy periodical configuration with bell-shaped time evolution. The seasonal pattern of this group is driven by forces related to high environmental wealth and tertiary specialization but low transport integration and tourism profile. Finally, the fourth and largest in size modularity group has the highest seasonality, with a pattern described on average by an approximately cyclical pattern and a circular geographical configuration. The seasonal pattern of this group is driven by forces related to rich sea geomorphology, environmental and cultural wealth, and transport integration, all of which describe the dominant $3 \mathrm{~S}$ model of the tourism product in Greece. Overall, the analysis supports multidisciplinary and synthetic research in the modeling of tourism-seasonality, which is a composite socio-economic phenomenon of high complexity, and also promotes complex network analysis in the study of socio-economic systems by providing insights into the physical conceptualization of community detection in real-world applications.

Author Contributions: Conceptualization, D.T.; Methodology, D.T.; Software, D.T. and T.K.; Validation, D.T., T.K. and S.P.; Formal Analysis, D.T., T.K. and S.P.; Investigation, D.T., T.K. and S.P.; Resources, D.T., T.K. and S.P.; Data Curation, T.K.; Writing-Original Draft Preparation, D.T. and T.K.; Writing-Review \& Editing, D.T., T.K. and S.P.; Visualization, D.T. and T.K.; Supervision, D.T. and S.P. All authors have read and agreed to the published version of the manuscript.

Funding: This research is co-financed by Greece and the European Union (European Social FundESF) through the Operational Programme "Human Resources Development, Education and Lifelong Learning 2014-2020" in the context of the project "Analysis and methodological approach of tourismseasonality for the Greek regions" (MIS 5048961).

Data Availability Statement: Data are available within the main text and Appendix A.

Acknowledgments: The authors thank the anonymous reviewers for their valuable comments that significantly improved the quality of the paper.

Conflicts of Interest: The authors declare no conflict of interest. 


\section{Appendix A}

Table A1. Literature table showing major conceptual aspects of tourism seasonality.

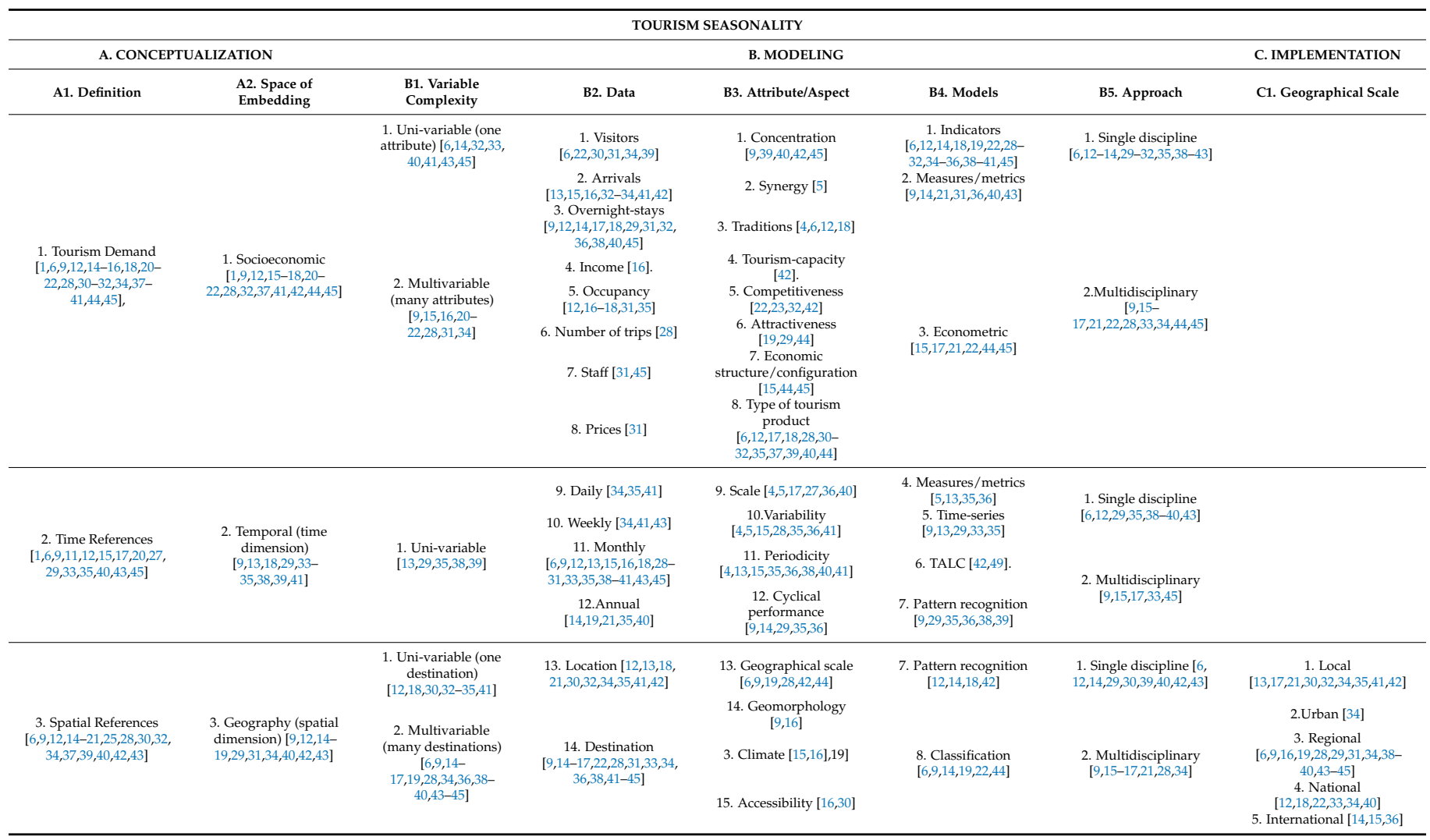

Table A2. The seasonality variables participating in the analysis and correspond to the 51 Greek prefectures.

\begin{tabular}{cccccccc}
\hline Prefecture & $\begin{array}{c}\text { Variable } \\
\text { Code }\end{array}$ & Prefecture & $\begin{array}{c}\text { Variable } \\
\text { Code }\end{array}$ & Prefecture & $\begin{array}{c}\text { Variable } \\
\text { Code }\end{array}$ & $\begin{array}{c}\text { Prefecture } \\
\text { Variable } \\
\text { Code }\end{array}$ \\
\hline ACHAIA & 34 & EVROS & 3 & KEFALONIA & 32 & PIERIA & 10 \\
AITOLOAKARNANIA & 35 & EVRYTANIA & 28 & KERKYRA & 30 & PREVEZA \\
ARGOLIDA & 38 & FLORINA & 16 & KILKIS & 8 & RETHYMNO & 50 \\
ARKADIA & 37 & FOKIDA & 29 & KORINTHIA & 39 & RODOPI \\
ARTA & 18 & FTHIOTIDA & 25 & KOZANI & 13 & SAMOS & 44 \\
ATTIKI & 42 & GREVENA & 14 & LAKONIA & 40 & SERRES & 11 \\
CHALKIDIKI & 12 & HELEIA & 36 & LARISSA & 21 & THESPOTIA & 19 \\
CHANIA & 51 & HERAKLION & 48 & LASITHI & 49 & THESSALONIKI & 6 \\
CHIOS & 45 & HMATHIA & 7 & LEFKADA & 33 & TRIKALA \\
CYCLADES & 46 & IOANNINA & 17 & LESVOS & 43 & VIOTIA \\
DODECANESE & 47 & KARDITSA & 22 & MAGNESIA & 23 & XANTHI \\
DRAMA & 2 & KASTORIA & 15 & MESSENIA & 41 & ZAKEENTHOS \\
EVIA & 27 & KAVALA & 4 & PELLA & 9 & 31 \\
\hline
\end{tabular}


Table A3. The socio-economic and geographical (SEG) variables * used to determine the socio-economic profiles of the modularity groups of Figure 5.

\begin{tabular}{|c|c|c|c|}
\hline Code & Variable's Symbol & Description & Source \\
\hline SEG.1 & LAT & Latitude, defined by the geographical center of the prefecture. & [63] \\
\hline SEG.2 & LONG & Longitude, defined by the geographical center of the prefecture. & [63] \\
\hline SEG.3 & RSI & $\begin{array}{l}\text { The Relative Seasonality Index of the prefectures' seasonality } \\
\text { patterns }\end{array}$ & [9] \\
\hline SEG.4 & GINI & The Gini coefficient of the prefectures' seasonality patterns & [9] \\
\hline SEG.5 & ROAD DENSITY & $\begin{array}{l}\text { The road density (road length/area) of each prefecture (measured } \\
\text { in } \mathrm{km} / \mathrm{km}^{2} \text { ). }\end{array}$ & [64-68] \\
\hline SEG.6 & ROAD LENGTH & The road length of each prefecture (measured in $\mathrm{km}$ ). & [64-68] \\
\hline SEG.7 & COASTAL & $\begin{array}{l}\text { Dummy variable capturing coastal configuration }(1=\text { coastal } \\
\text { perfectures; } 0=\text { non-coastal perfectures }) .\end{array}$ & [67] \\
\hline SEG.8 & ISLAND & Dummy variable capturing island configuration. & [59] \\
\hline SEG.9 & INLAND & Dummy variable capturing inland configuration. & [59] \\
\hline SEG.10 & RAIL & The length of the rail network. & {$[48,68]$} \\
\hline SEG.11 & PORTS & The number of ports. & {$[59,68]$} \\
\hline SEG.12 & AIRPORTS & The number of airports. & {$[59,68]$} \\
\hline SEG.13 & AREA & The geographical area (measured in $\mathrm{km}^{2}$ ). & [59] \\
\hline SEG.14 & POP & The regional population (2011 national census). & [65] \\
\hline SEG.15 & URB & $\begin{array}{l}\text { The urbanization level (i.e., the proportion of the capital city's } \\
\text { population to the regional population). }\end{array}$ & {$[65]$} \\
\hline SEG.16 & GDP & Gross Domestic Product. & {$[65]$} \\
\hline SEG.17 & Human Capital & $\begin{array}{l}\text { Defined by the proportion of labor-force (i.e., population between } \\
18 \text { and } 65 \text { years old) to the total population. }\end{array}$ & [1] \\
\hline SEG.18 & $\mathrm{A}_{\mathrm{SEC}}$ & The specialization (\% of the GDP) in the primary (A) sector. & {$[66,69]$} \\
\hline SEG.19 & $\mathrm{B}_{\mathrm{SEC}}$ & The specialization (\% of the GDP) in the secondary (B) sector. & {$[66,69]$} \\
\hline SEG.20 & $\mathrm{C}_{\mathrm{SEC}}$ & The specialization (\% of the GDP) in the tertiary (C) sector. & {$[66,69]$} \\
\hline SEG.21 & TOURISM GDP & The specialization ( $\%$ of the GDP) in the tourism sector. & {$[66]$} \\
\hline SEG.22 & TILLING LAND & The proportion of the tilling-land areas to the total regional area. & {$[67]$} \\
\hline SEG.23 & FORESTS & The proportion of forest-areas to the total regional area. & [67] \\
\hline SEG.24 & INLAND WATERS & The proportion of the inland-water-areas to the total regional area. & [67] \\
\hline SEG.25 & INDUSTRIAL AREA & The proportion of the industrial-areas to the total regional area. & {$[67,69]$} \\
\hline SEG.26 & LAND AREA & $\begin{array}{l}\text { The proportion of (non-mountainous) land-areas to the total } \\
\text { regional area. }\end{array}$ & [67] \\
\hline SEG.27 & SEMI MOUNTAIN AREA & $\begin{array}{l}\text { The proportion of the semi-mountain areas to the total regional } \\
\text { area. }\end{array}$ & [67] \\
\hline SEG.28 & MOUNTAIN AREA & The proportion of the mountain-areas to the total regional area. & [67] \\
\hline SEG.29 & MOUNT ACTIVITIES & $\begin{array}{l}\text { The number of mountain-activities (e.g., walking paths, mount } \\
\text { sports, climb fields). }\end{array}$ & [67] \\
\hline SEG.30 & CLIMB FIELDS & The number of climb-fields. & [67] \\
\hline SEG.31 & MOUNT ROUTES & The number of mountain-routes. & [67] \\
\hline
\end{tabular}


Table A3. Cont.

\begin{tabular}{|c|c|c|c|}
\hline Code & Variable's Symbol & Description & Source \\
\hline SEG.32 & RAFTING POINTS & The number of rafting-points. & [67] \\
\hline SEG.33 & CANYONING POINTS & The number of canyoning-points. & [67] \\
\hline SEG.34 & SKI CENTERS & The number ski-centers. & [67] \\
\hline SEG.35 & SKI ROUTES LENGTH & The length of the ski-routes (measured in km). & [67] \\
\hline SEG.36 & RESTAURANTS & The number of restaurants. & [67] \\
\hline SEG.37 & NATURA AREA & $\begin{array}{l}\text { The geographical area of the Natura parks (i.e., environmentally } \\
\text { protected areas). }\end{array}$ & [67] \\
\hline SEG.38 & WOODLANDS PARKS & The number of woodland-parks. & [67] \\
\hline SEG.39 & HOTELS & The number of hotels. & [66] \\
\hline SEG.40 & CAMPING & The number of camping sites. & [66] \\
\hline SEG.41 & BLUE FLAG & The number of beaches that are granted a blue flag. & [66] \\
\hline SEG.42 & BEACHES & The number of organized beaches. & [66] \\
\hline SEG.43 & ANC MONUMENTS & The number of ancient monument sites. & [66] \\
\hline SEG.44 & UNESCO MONUMENTS & The number of UNESCO monument sites. & [66] \\
\hline SEG.45 & HOTEL BEDS & The number of hotel beds (bed capacity). & [66] \\
\hline SEG.46 & ROOMS & The number of rooms to let (non-hotel accommodation). & [66] \\
\hline SEG.47 & ROOMS BEDS & The number of rooms' beds (non-hotel accommodation capacity). & [66] \\
\hline SEG.48 & ACCOMMODATION BEDS & The number of other types of accommodation beds. & [66] \\
\hline SEG.49 & CULTURAL RESOURCES & The number of cultural-resources sites. & [67] \\
\hline SEG.50 & BEACHES LENGTH & The length of beaches. & [67] \\
\hline SEG.51 & SAND BEACHES LENGTH & The length of sand beaches. & [67] \\
\hline
\end{tabular}

* Variables of length 51. Each element within a variable corresponds to a Greek prefecture.

Table A4. "Min-max" table showing the minimum and maximum performance of the modularity-groups for the available socio-economic and geographical (SEG) attributes.

\begin{tabular}{|c|c|c|c|c|c|}
\hline \multicolumn{6}{|c|}{ MODULARITY GROUPS } \\
\hline Variable Code & Variable Name & $(0,0,1)$ & $(1,1,0)$ & $(1,1,1)$ & $(2,2,0)$ \\
\hline \multicolumn{6}{|c|}{ GEOGRAPHIC } \\
\hline SEG1 & LAT & MAX & MAX & & MIN \\
\hline SEG2 & LONG & MAX & MIN & & MAX \\
\hline SEG3 & COASTAL & & MIN & MIN & MAX \\
\hline SEG4 & ISLAND & & MIN & MIN & MAX \\
\hline SEG5 & INLAND & & MIN & MAX & \\
\hline SEG6 & AREA & MIN & MAX & & MIN \\
\hline SEG7 & TILLING LAND & & MAX & MIN & MIN \\
\hline SEG8 & FORESTS & & MAX & & MIN \\
\hline SEG9 & INLAND WATERS & MIN & MAX & & MIN \\
\hline SEG10 & LAND AREA & & MAX & MIN & \\
\hline SEG11 & $\begin{array}{c}\text { SEMI MOUNTAIN } \\
\text { AREA }\end{array}$ & MIN & MAX & MIN & MIN \\
\hline SEG12 & $\begin{array}{c}\text { MOUNTAIN } \\
\text { AREA }\end{array}$ & & MAX & & MIN \\
\hline \multicolumn{6}{|c|}{ SEASONALITY } \\
\hline SEG13 & RSI & MIN & MIN & & MAX \\
\hline SEG14 & GINI & MIN & MIN & MIN & MAX \\
\hline
\end{tabular}


Table A4. Cont.

\begin{tabular}{|c|c|c|c|c|c|}
\hline \multirow[b]{2}{*}{ Variable Code } & \multirow[b]{2}{*}{ Variable Name } & \multicolumn{4}{|c|}{ MODULARITY GROUPS } \\
\hline & & $(0,0,1)$ & $(1,1,0)$ & $(1,1,1)$ & $(2,2,0)$ \\
\hline \multicolumn{6}{|c|}{ TRANSPORT } \\
\hline SEG15 & ROAD DENSITY & & MIN & & MAX \\
\hline SEG16 & ROAD LENGTH & & & & \\
\hline SEG17 & RAIL & & MAX & & MIN \\
\hline SEG18 & PORTS & MIN & MIN & MIN & MAX \\
\hline SEG19 & AIRPORTS & & MAX & MIN & \\
\hline \multicolumn{6}{|c|}{ DEMOGRAPHIC } \\
\hline SEG20 & POP & & MAX & MIN & \\
\hline SEG21 & URB & MAX & MIN & MAX & MAX \\
\hline SEG22 & $\begin{array}{l}\text { HUMAN } \\
\text { CAPITAL }\end{array}$ & & MAX & MIN & \\
\hline \multicolumn{6}{|c|}{ PRODUCTIVITY } \\
\hline SEG23 & GDP & & MAX & MIN & \\
\hline SEG24 & $\mathrm{A}_{\mathrm{SEC}}$ & & MIN & & MAX \\
\hline SEG25 & $\mathrm{B}_{\mathrm{SEC}}$ & MIN & MAX & MIN & MIN \\
\hline SEG26 & $\mathrm{C}_{\mathrm{SEC}}$ & & MIN & MAX & MAX \\
\hline SEG27 & TOURISM GDP & & MAX & MIN & \\
\hline SEG28 & $\begin{array}{l}\text { INDUSTRIAL } \\
\text { AREA }\end{array}$ & MIN & MAX & MIN & MIN \\
\hline \multicolumn{6}{|c|}{ TOURISM } \\
\hline SEG29 & HOTELS & & MIN & MIN & MAX \\
\hline SEG30 & HOTEL BEDS & & MIN & MIN & MAX \\
\hline SEG31 & ROOMS & & MIN & MIN & MAX \\
\hline SEG32 & ROOMS BEDS & & MIN & MIN & MAX \\
\hline SEG33 & $\begin{array}{l}\text { ACCOMMODATION } \\
\text { BEDS }\end{array}$ & & MIN & MIN & MAX \\
\hline SEG34 & CAMPING & MIN & MIN & MIN & MAX \\
\hline SEG35 & RESTAURANTS & & MIN & MIN & MAX \\
\hline SEG36 & $\begin{array}{c}\text { MOUNT } \\
\text { ACTIVITIES }\end{array}$ & & MAX & MIN & MIN \\
\hline SEG37 & CLIMB FIELDS & MAX & MIN & MAX & MAX \\
\hline SEG38 & MOUNT ROUTES & & MAX & MIN & MIN \\
\hline SEG39 & RAFTING POINTS & & & & \\
\hline SEG40 & $\begin{array}{l}\text { CANYONING } \\
\text { POINTS }\end{array}$ & & MIN & & MAX \\
\hline SEG41 & SKI CENTERS & MAX & MIN & MAX & MIN \\
\hline SEG42 & $\begin{array}{l}\text { SKI ROUTES } \\
\text { LENGTH }\end{array}$ & MAX & MIN & & \\
\hline \multicolumn{6}{|c|}{ ENVIRONMENTAL } \\
\hline SEG43 & NATURA AREA & MAX & MIN & MAX & MAX \\
\hline SEG44 & $\begin{array}{l}\text { WOODLANDS } \\
\text { PARKS }\end{array}$ & MAX & MIN & & \\
\hline SEG45 & $\begin{array}{l}\text { BLUE FLAG } \\
\text { BEACHES }\end{array}$ & & MIN & MIN & MAX \\
\hline SEG46 & BEACHES & MIN & MIN & MIN & MAX \\
\hline SEG47 & $\begin{array}{l}\text { BEACHES } \\
\text { LENGTH }\end{array}$ & MIN & MIN & MIN & MAX \\
\hline SEG48 & $\begin{array}{c}\text { SAND BEACHES } \\
\text { LENGTH }\end{array}$ & MIN & MIN & MIN & MAX \\
\hline \multicolumn{6}{|c|}{ CULTURAL } \\
\hline SEG49 & $\begin{array}{c}\text { ANC } \\
\text { MONUMENTS }\end{array}$ & & MIN & & MAX \\
\hline SEG50 & $\begin{array}{c}\text { UNESCO } \\
\text { MONUMENTS }\end{array}$ & & MIN & MIN & MAX \\
\hline SEG51 & $\begin{array}{l}\text { CULTURAL } \\
\text { RESOURCES }\end{array}$ & & MIN & & MAX \\
\hline
\end{tabular}

a. Defined by the max-value (+) filter of Figure 3. b. Defined by the min-value (-) filter of Figure 3. 


\section{References}

1. Polyzos, S. Regional Development; Kritiki: Athens, Greece, 2019; ISBN 9789602187302.

2. Mastronardi, L.; Cavallo, A. The Spatial Dimension of Income Inequality: An Analysis at Municipal Level. Sustainability 2020, 12, 1622. [CrossRef]

3. Vo, D.H.; Nguyen, T.C.; Tran, N.P.; Vo, A.T. What Factors Affect Income Inequality and Economic Growth in Middle-Income Countries? J. Risk Financial Manag. 2019, 12, 40. [CrossRef]

4. Charles-Edwards, E.; Bell, M. Seasonal Flux in Australia's Population Geography: Linking Space and Time. Popul. Space Place 2013, 21, 103-123. [CrossRef]

5. Romão, J.; Saito, H. A spatial analysis on the determinants of tourism performance in Japanese Prefectures. Asia-Pac. J. Reg. Sci. 2017, 1, 243-264. [CrossRef]

6. Batista e Silva, F.; Kavalov, B.; Lavalle, C. Socio-Economic Regional Microscope Series-Territorial Patterns of Tourism Inten-Sity and Seasonality in the EU; Publications Office of the European Union: Luxembourg, 2019. [CrossRef]

7. Ulbrich, P.; de Albuquerque, J.P.; Coaffee, J. The Impact of Urban Inequalities on Monitoring Progress towards the Sustainable Development Goals: Methodological Considerations. ISPRS Int. J. Geo-Inf. 2018, 8, 6. [CrossRef]

8. Băndoi, A.; Jianu, E.; Enescu, M.; Axinte, G.; Tudor, S.; Firoiu, D. The Relationship between Development of Tourism, Quality of Life and Sustainable Performance in EU Countries. Sustainability 2020, 12, 1628. [CrossRef]

9. Tsiotas, D.; Krabokoukis, T.; Polyzos, S. Detecting Interregional patterns in tourism-seasonality of Greece: A principal components analysis approach. Reg. Sci. Inq. 2020, 12, 91-112.

10. Krabokoukis, T.; Polyzos, S. An Investigation of Factors Determining the Tourism Attractiveness of Greece's Prefectures. J. Knowl. Econ. 2020. [CrossRef]

11. Saarinen, J.; Rogerson, C.M.; Hall, C.M. Geographies of tourism development and planning. Tour. Geogr. 2017, 19, 307-317. [CrossRef]

12. Butler, R.W. Seasonality in tourism: Issues and implications. In Tourism: The State of the Art; Seaton, A., Ed.; Wiley: Chichester, UK, 1994; ISBN 978-0471950929.

13. Gil-Alana, L.A. International Arrivals in the Canary Islands: Persistence, Long Memory, Seasonality and other Implicit Dynamics. Tour. Econ. 2010, 16, 287-302. [CrossRef]

14. Ferrante, M.; Magno, G.L.L.; De Cantis, S. Measuring tourism seasonality across European countries. Tour. Manag. 2018, 68, 220-235. [CrossRef]

15. Duro, J.A.; Turrión-Prats, J. Tourism seasonality worldwide. Tour. Manag. Perspect. 2019, 31, 38-53. [CrossRef]

16. Sæpórsdóttir, A.D.; Hall, C.M.; Stefánsson, P. Senses by Seasons: Tourists' Perceptions Depending on Seasonality in Popular Nature Destinations in Iceland. Sustainability 2019, 11, 3059. [CrossRef]

17. Corluka, G.; Mikinac, K.; Milenkovska, A. Classification of tourist season in coastal tourism. UTMS J. Econ. 2016, 7, 71-83.

18. Butler, R.W. Seasonality in Tourism: Issues and Implication. In Seasonality in Tourism; Baum, T., Lundtorp, S., Eds.; Elsevier Ltd.: Oxford, UK, 2001; ISBN 9780080436746.

19. Fang, Y.; Yin, J. National Assessment of Climate Resources for Tourism Seasonality in China Using the Tourism Climate Index. Atmosphere 2015, 6, 183-194. [CrossRef]

20. De Almeida, A.L.; Kastenholz, E. Towards a Theoretical Model of Seasonal Tourist Consumption Behaviour. Tour. Plan. Dev. 2018, 16, 533-555. [CrossRef]

21. Choe, Y.; Kim, H.; Joun, H.-J. Differences in Tourist Behaviors across the Seasons: The Case of Northern Indiana. Sustainability 2019, 11, 4351. [CrossRef]

22. Liu, Y.; Li, Y.; Parkpian, P. Inbound tourism in Thailand: Market form and scale differentiation in ASEAN source countries. Tour. Manag. 2018, 64, 22-36. [CrossRef]

23. Gómez-Vega, M.; Picazo-Tadeo, A.J. Ranking world tourist destinations with a composite indicator of competitiveness: To weigh or not to weigh? Tour. Manag. 2019, 72, 281-291. [CrossRef]

24. Niavis, S.; Tsiotas, D. Decomposing the price of the cruise product into tourism and transport attributes: Evidence from the Mediterranean market. Tour. Manag. 2018, 67, 98-110. [CrossRef]

25. Tsiotas, D.; Niavis, S.; Sdrolias, L. Operational and geographical dynamics of ports in the topology of cruise networks: The case of Mediterranean. J. Transp. Geogr. 2018, 72, 23-35. [CrossRef]

26. Niavis, S.; Tsiotas, D. Assessing the tourism performance of the Mediterranean coastal destinations: A combined efficiency and effectiveness approach. J. Destin. Mark. Manag. 2019, 14, 100379. [CrossRef]

27. Romão, J.; Guerreiro, J.; Rodrigues, P.M.M. Territory and Sustainable Tourism Development: A Space-Time Analysis on European Regions. Region 2017, 4, 1-17. [CrossRef]

28. Fernández-Morales, A.; Cisneros-Martínez, J.D.; McCabe, S. Seasonal concentration of tourism demand: Decomposition analysis and marketing implications. Tour. Manag. 2016, 56, 172-190. [CrossRef]

29. Cuccia, T.; Rizzo, I. Tourism seasonality in cultural destinations: Empirical evidence from Sicily. Tour. Manag. 2011, 32, 589-595. [CrossRef]

30. Lundtorp, S.; Rassing, C.R.; Wanhill, S. The off-Season is 'No Season': The Case of the Danish Island of Bornholm. Tour. Econ. 1999, 5, 49-68. [CrossRef] 
31. Martín, J.M.M.; Fernández, J.A.S. Comprehensive evaluation of the tourism seasonality using a synthetic DP2 indicator. Tour. Geogr. 2019, 21, 284-305. [CrossRef]

32. Andriotis, K. Seasonality in Crete: Problem or a Way of Life? Tour. Econ. 2005, 11, 207-224. [CrossRef]

33. Assaf, A.G.; Barros, C.P.; Gil-Alana, L.A. Persistence in the Short- and Long-Term Tourist Arrivals to Australia. J. Travel Res. 2010, 50, 213-229. [CrossRef]

34. Pórhallsdóttir, G.; Ólafsson, R. A method to analyse seasonality in the distribution of tourists in Iceland. J. Outdoor Recreat. Tour. 2017, 19, 17-24. [CrossRef]

35. De Cantis, S.; Ferrante, M.; Vaccina, F. Seasonal Pattern and Amplitude-A Logical Framework to Analyse Seasonality in Tourism: An Application to Bed Occupancy in Sicilian Hotels. Tour. Econ. 2011, 17, 655-675. [CrossRef]

36. Magno, G.L.L.; Ferrante, M.; De Cantis, S. A new index for measuring seasonality: A transportation cost approach. Math. Soc. Sci. 2017, 88, 55-65. [CrossRef]

37. Koenig-Lewis, N.; Bischoff, E.E. Seasonality research: The state of the art. Int. J. Tour. Res. 2005, 7, 201-219. [CrossRef]

38. Fernández-Morales, A. Decomposing seasonal concentration. Ann. Tour. Res. 2003, 30, 942-956. [CrossRef]

39. Cisneros-Martínez, J.D.; Fernández-Morales, A. Cultural tourism as tourist segment for reducing seasonality in a coastal area: The case study of Andalusia. Curr. Issues Tour. 2013, 18, 765-784. [CrossRef]

40. Duro, J.A. Seasonality of hotel demand in the main Spanish provinces: Measurements and decomposition exercises. Tour. Manag. 2016, 52, 52-63. [CrossRef]

41. Rosselló, J.; Sansó, A. Yearly, monthly and weekly seasonality of tourism demand: A decomposition analysis. Tour. Manag. 2017, 60, 379-389. [CrossRef]

42. Terkenli, T.S. Human Activity in Landscape Seasonality: The Case of Tourism in Crete. Landsc. Res. 2005, 30, 221-239. [CrossRef]

43. Ahas, R.; Aasa, A.; Mark, Ü.; Pae, T.; Kull, A. Seasonal tourism spaces in Estonia: Case study with mobile positioning data. Tour. Manag. 2007, 28, 898-910. [CrossRef]

44. Connell, J.; Page, S.J.; Meyer, D. Visitor attractions and events: Responding to seasonality. Tour. Manag. 2015, 46, 283-298. [CrossRef]

45. Cisneros-Martínez, J.D.; McCabe, S.; Morales, A.F. The contribution of social tourism to sustainable tourism: A case study of seasonally adjusted programmes in Spain. J. Sustain. Tour. 2018, 26, 85-107. [CrossRef]

46. World Bank. World Development Indicators: Travel and Tourism. 2020. Available online: http://wdi.worldbank.org/table/6.14 (accessed on 18 December 2020).

47. INSETE. The Contribution of Tourism to the Greek Economy. 2020. Available online: https://insete.gr/bi/ (accessed on 18 December 2020).

48. Tsiotas, D. The imprint of tourism on the topology of maritime networks: Evidence from Greece. Anatolia 2016, 28, 52-68. [CrossRef]

49. Polyzos, S.; Tsiotas, D.; Kantlis, A. Determining the Tourism Developmental Dynamics of the Greek Regions, by using TALC Theory, Tourismos: An International Multidisciplinary. J. Tour. 2013, 8, 159-178.

50. Kalantzi, O.; Tsiotas, D.; Polyzos, S. The contribution of tourism in national economies: Evidence of Greece. EJBSS 2016, 5, 41-64.

51. Barabási, A.-L. Network science. Philos. Trans. R. Soc. A Math. Phys. Eng. Sci. 2013, 371, 20120375. [CrossRef] [PubMed]

52. Newman, M.E.J. Networks: An Introduction; Oxford University Press: Oxford, UK, 2010.

53. Boccaletti, S.; Bianconi, G.; Criado, R.; del Genio, C.; Gómez-Gardeñes, J.; Romance, M.; Sendiña-Nadal, I.; Wang, Z.; Zanin, M. The structure and dynamics of multilayer networks. Phys. Rep. 2014, 544, 1-122. [CrossRef]

54. Tsiotas, D. Detecting different topologies immanent in scale-free networks with the same degree distribution. Proc. Natl. Acad. Sci. USA 2019, 116, 6701-6706. [CrossRef]

55. Baggio, R.; Valeri, M. Network science and sustainable performance of family businesses in tourism. J. Fam. Bus. Manag. 2020. [CrossRef]

56. Valeri, M.; Baggio, R. Italian tourism intermediaries: A social network analysis exploration. Curr. Issues Tour. 2020, 1-14. [CrossRef]

57. Valeri, M.; Baggio, R. Social network analysis: Organizational implications in tourism management. Int. J. Organ. Anal. 2020. [CrossRef]

58. Tsiotas, D.; Tselios, V. Understanding the uneven spread of COVID-19 in the context of the global interconnected economy. arXiv 2021, arXiv:2101.11036.

59. Hellenic Statistical Authority_ELSTAT 2019a. Number of Monthly Overnight-Stays in the Greek Prefectures for the Period 1998-2018. Available online: www.statistics.gr (accessed on 18 December 2020).

60. Walpole, R.E.; Myers, R.H.; Myers, S.L.; Ye, K. Probability \& Statistics for Engineers E Scientists, 9th ed.; Prentice Hall Publications: New York, NY, USA, 2012; ISBN 9780321629111.

61. Fortunato, S. Community detection in graphs. Phys. Rep. 2010, 486, 75-174. [CrossRef]

62. Blondel, V.D.; Guillaume, J.-L.; Lambiotte, R.; Lefebvre, E. Fast unfolding of communities in large networks. J. Stat. Mech. Theory Exp. 2008, 2008, P10008. [CrossRef]

63. Google Maps. Google Mapping Services. 2020. Available online: www.google.gr/maps?hl=el (accessed on 18 December 2020).

64. Tsiotas, D. Links between network topology and socio-economic framework of railway transport: Evidence from Greece. J. Eng. Sci. Technol. Rev. 2017, 10, 175-187. [CrossRef] 
65. Hellenic Statistical Authority-ELSTAT. Population and Social Conditions. 2019. Available online: https://www.statistics.gr/el/ statistics/pop (accessed on 3 June 2020).

66. Hellenic Statistical Authority-ELSTAT. Economy, Indices. 2019. Available online: https://www.statistics.gr/el/statistics/eco (accessed on 3 June 2020).

67. Hellenic Statistical Authority-ELSTAT. Environment and Energy. 2019. Available online: https://www.statistics.gr/el/statistics/ env (accessed on 3 June 2020).

68. Polyzos, S.; Tsiotas, D. The contribution of transport infrastructures to the economic and regional development. Theor. Empir. Res. Urban Manag. 2020, 15, 5-23.

69. Polyzos, S.; Tsiotas, D. Measuring structural changes of the Greek economy during the period of economic crisis. Manag. Res. Pract. 2020, 12, 5-24. 